\title{
A Physically-Based Equivalent Circuit Model for the Impedance of a LiFePO4/Graphite 26650 Cylindrical Cell
}

Scipioni, Roberto; Jørgensen, Peter Stanley; Graves, Christopher R.; Hjelm, Johan; Jensen, Søren Højgaard

Published in:

Journal of The Electrochemical Society

Link to article, DOI:

10.1149/2.1071709jes

Publication date:

2017

Document Version

Publisher's PDF, also known as Version of record

Link back to DTU Orbit

Citation (APA):

Scipioni, R., Jørgensen, P. S., Graves, C. R., Hjelm, J., \& Jensen, S. H. (2017). A Physically-Based Equivalent Circuit Model for the Impedance of a LiFePO/Graphite 26650 Cylindrical Cell. Journal of The Electrochemical Society, 164(9), A2017-A2030. https://doi.org/10.1149/2.1071709jes

\section{General rights}

Copyright and moral rights for the publications made accessible in the public portal are retained by the authors and/or other copyright owners and it is a condition of accessing publications that users recognise and abide by the legal requirements associated with these rights.

- Users may download and print one copy of any publication from the public portal for the purpose of private study or research.

- You may not further distribute the material or use it for any profit-making activity or commercial gain

- You may freely distribute the URL identifying the publication in the public portal 


\title{
A Physically-Based Equivalent Circuit Model for the Impedance of a $\mathrm{LiFePO}_{4} /$ Graphite 26650 Cylindrical Cell
}

\author{
Roberto Scipioni,,,z Peter S. Jørgensen, Christopher Graves, Johan Hjelm, \\ and Søren H. Jensen*,z
}

DTU Energy, Department of Energy Conversion and Storage, Technical University of Denmark, 4000 Roskilde, Denmark

\begin{abstract}
In this work an Equivalent Circuit Model (ECM) is developed and used to model impedance spectra measured on a commercial 26650 $\mathrm{LiFePO}_{4} / \mathrm{Graphite}$ cylindrical cell. The ECM is based on measurements and modeling of impedance spectra recorded separately on cathode $\left(\mathrm{LiFePO}_{4}\right)$ and anode (Graphite) samples, harvested from the commercial cell. Modeling of the single-electrode impedance spectra provided information about the electronic and ionic resistance in the porous composite electrodes, as well as the solid state diffusion. Focused Ion Beam (FIB)/Scanning Electron Microscopy (SEM) of anode and cathode samples was used to make 3-D maps of the electrode microstructures and to obtain microstructural data for the ECM. The complementary analysis was crucial for the resolution of the single electrode impedance parameters and the proposal and validation of a new equivalent circuit used to model the full commercial battery impedance.

(C) The Author(s) 2017. Published by ECS. This is an open access article distributed under the terms of the Creative Commons Attribution Non-Commercial No Derivatives 4.0 License (CC BY-NC-ND, http://creativecommons.org/licenses/by-nc-nd/4.0/), which permits non-commercial reuse, distribution, and reproduction in any medium, provided the original work is not changed in any way and is properly cited. For permission for commercial reuse, please email: oa@electrochem.org. [DOI: 10.1149/2.1071709jes] All rights reserved.

(cC) BY-NC-ND
\end{abstract}

Manuscript submitted May 9, 2017; revised manuscript received June 26, 2017. Published July 14, 2017.

The cylindrical cell continues to be one of the most widely used packaging styles for primary and secondary batteries. The advantages are ease of manufacture and good mechanical stability. The tubular cylinder can withstand high internal pressures without deforming. ${ }^{1}$ Even though cylindrical cells leave air cavities when placed sideby-side, they can have a higher energy density than prismatic/pouch Li-ion cells. ${ }^{1}$ The higher energy density of the cylindrical cell compensates for its poor packing abilities and the empty space can be used for cooling to improve thermal management.

Electrochemical Impedance Spectroscopy (EIS) is one of the most powerful tools for the study of electrochemical systems ${ }^{2-4}$ and is especially suited for extraction of kinetic and transport properties of the electrode materials and for studies of aging mechanisms. ${ }^{5-9}$ In the past few years several papers on impedance modelling of porous battery electrode have been published, ${ }^{610-12}$ and various equivalent circuit models (ECMs) have been developed and proposed in literature to describe the impedance response of single $\mathrm{LiFePO}_{4}{ }^{8,13,14}$ and Graphite electrodes. ${ }^{15-19}$ Most of these have been obtained by isolating the polarization processes that occur at the single electrode from symmetrical cell configurations ${ }^{13,14,20}$ or three-electrode configurations. ${ }^{18,21}$

In order to study electrode ageing mechanisms, Transmission Line Models (TLMs; a subset of ECMs) have previously been used to model the impedance response of porous electrodes infiltrated by a liquid electrolyte. ${ }^{15,20,22,23}$ One important ability of these TLMs is the calculation of ionic resistance in the infiltrated pores $R_{\text {ion } L}$. The electronic resistance $R_{e l}$ through the composite electrode is usually considered negligible compared to the ionic resistance. In this case applies a simplified TLM without $R_{e l}$. $\mathrm{LiFePO}_{4}$ is a poor ionic and electronic conductor, ${ }^{24}$ and is therefore coated and mixed with carbon additives to improve the electronic conductivity of the electrode..$^{25}$ Despite this, the electronic resistance of such composite electrode is not always negligible, and it can change considerably during degradation. ${ }^{21}$

Solid state diffusion inside electrode particles also plays an important role for the electrode performance and is usually modeled by a Warburg element. ${ }^{20}$ The two TLMs presented in this work models respectively the impedance of the anode and cathode, and incorporate an equivalent circuit element $\varsigma$ which describes the surface reaction at the electrode/electrolyte interface, as well as the solid state diffusion. The difference between the two TLMs reflects the different properties of the two composite electrodes. The two TLMs are subsequently combined in series and inserted in the final ECM that is used to model the impedance response of the full cell. The ECM incorporates elements describing the dominating loss mechanisms and is used to determine both kinetic and transport parameters of the electrode materials in the investigated cylindrical cell.

\section{Methods and Materials}

Cell testing and disassembling.- $\mathrm{A}$ fresh $\mathrm{LiFePO}_{4} / \mathrm{Graphite}$ 26650 cylindrical cell with a nominal capacity of $2.5 \mathrm{Ah}$, denoted "26650CC", was cycled five times at a constant C-rate of 0.1 (250 $\mathrm{mA}$ ) and characterized by Electrochemical Impedance Spectroscopy (EIS) in a two-electrode setup using a Biologic VMP3 with Pstat/Gstat boards (test conditions shown in Table I).

In order to electrochemically test the cathode and anode in a threeelectrode configuration and resolve impedance contributions from each of the two electrodes, the 26650CC battery was dis-assembled in a glove box in the discharged state and the cathode and anode were unrolled. The cylindrical cell (Fig. 1a) consists of a $1.5 \mathrm{~m}$ $\mathrm{LiFePO}_{4} /$ carbonaceous additive (LFP/CB) positive electrode cast on either sides of an Aluminum foil, a $1.5 \mathrm{~m}$ Graphite (Gr) negative electrode cast on either sides of a Copper foil and 2 polymeric separators soaked with liquid electrolyte, schematically presented in Fig. 1b. The carbonaceous additive in the positive electrode is unknown, so we refer to it as Carbon Black (CB), in order to distinguish it from the graphite in the negative electrode $(\mathrm{Gr})$. The total area of each of the battery electrodes and separators was $1950 \mathrm{~cm}^{2}$. The two electrode foils were rinsed with diethyl carbonate and vacuum dried at $120^{\circ} \mathrm{C}$ in order to remove the liquid electrolyte. Subsequently four circular electrodes with a diameter of $18 \mathrm{~mm}\left(\right.$ area $\left.=2.55 \mathrm{~cm}^{2}\right)$ were punched out (two from the LFP/CB foil and two from the Gr foil) to be used for three-electrode testing and characterization by FIB/SEM.

Two out of the four circular electrodes (one LFP/CB and one Gr) were scratched with a spatula to remove the electrode layer on one side and then tested in two EL-CELL ECC-Combi 3-electrode setups. Lithium metal was used as counter and reference electrodes. The cells were assembled inside the glove box using glass fiber separator (Whatman GF/A) soaked with $200 \mu \mathrm{L}$ standard $1 \mathrm{M} \mathrm{LiPF}_{6}$ in $1: 1 \mathrm{v} / \mathrm{v}$ EC/DMC electrolyte solution from Sigma-Aldrich. Both cells were cycled at a constant C-rate, calculated as $0.1 \mathrm{C}$, for a few cycles to stabilize the electrode (see Table I for test conditions and sample names).

FIB/SEM tomography. - The electrodes LFP/CB2 and Gr2 (Table I) were prepared for FIB tomography by rinsing with diethyl carbonate 
Table I. Test conditions for the examined samples.

\begin{tabular}{ccccc} 
Sample & Current $(\mathrm{mA})$ & Approx. C-rate & Total cycle number & Comment \\
\hline 26650CC & 250 & 0.1 & 5 & Cylindrical Cell, 2-electrode setup \\
LFP/CB1 & 0.33 & 0.1 & 5 & Cathode, 3-electrode setup \\
LFP/CB2 & - & - & - & Cathode, used for FIB/SEM analysis \\
Gr1 & 0.33 & 0.1 & 5 & Anode, 3-electrode setup \\
Gr2 & - & - & - & Anode, used for FIB/SEM analysis
\end{tabular}
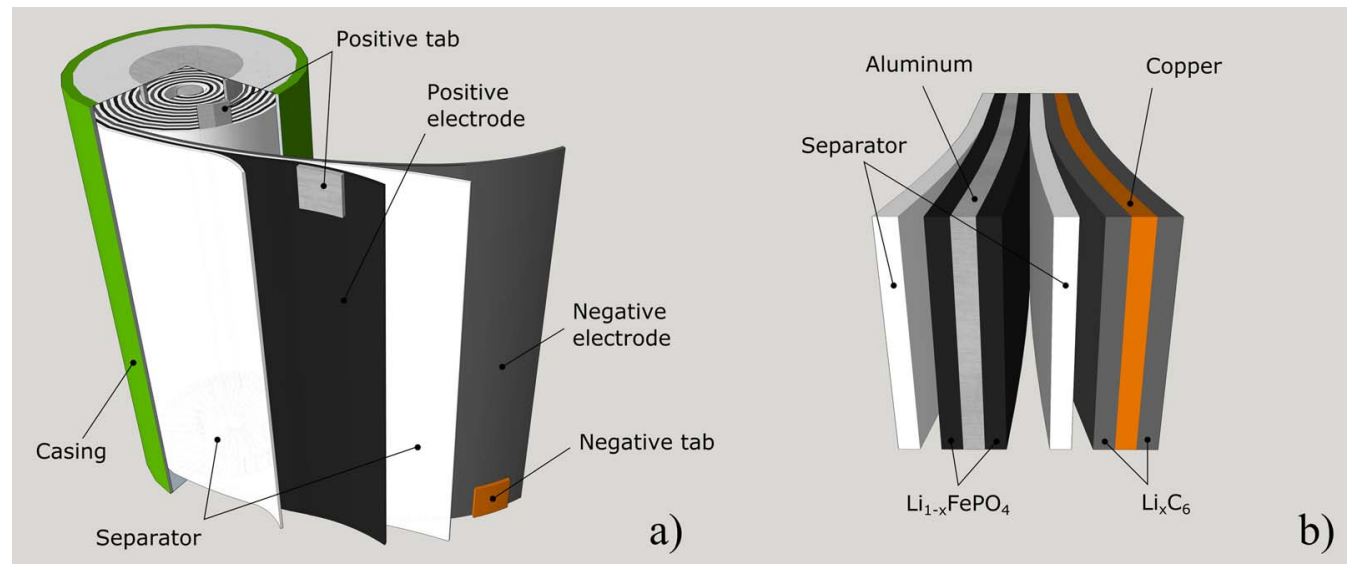

Figure 1. Schematic representation of a) $26650 \mathrm{CC}$ battery packaging design and b) $\mathrm{LiFePO}_{4} / \mathrm{Graphite}$ sandwich.

and vacuum infiltrated with a silicon resin (Wacker Chemie) for 30 minutes to improve phase contrast between CB particles and pores as described by Ender et al. ${ }^{26}$ Subsequently the samples were infiltrated with epoxy resin to enable high-quality grinding and polishing of the sample.

FIB tomography and SEM imaging of the two electrode samples were carried out on a Zeiss 1540XB Crossbeam microscope, using a lateral E-T (Everhart-Thornley) detector and an In-lens detector. A 3D dataset was collected from each of the two electrodes. Table II shows the volume sizes of the two 3D datasets. A Gallium FIB slicing probe of $2 \mathrm{nA}$ was used to mill the LFP/CB electrode with a slice thickness of $27 \mathrm{~nm}$. The slice thickness was calculated by measuring the progress of the milling front in each image during the stack alignment post processing step. For the Gr electrode the current for the Gallium FIB slicing probe was reduced to $1 \mathrm{nA}$ and the thickness of each slice was estimated to be $14 \mathrm{~nm}$. The Gr electrode is softer than the LFP/CB electrode. For this reason the FIB current had to be reduced to enable high-quality imaging for the $\mathrm{Gr}$ electrode dataset.

The LFP particles in the positive electrode are much smaller than the $\mathrm{Gr}$ particles in the negative one. Thus, in order to perform an accurate image segmentation of LFP particles - to be used for 3D reconstruction and particle size distribution (PSD) analysis - it was necessary to collect higher-resolution images. The serial sectioning imaging was performed at $1 \mathrm{kV}$ with a pixel size of $15 \times 15 \mathrm{~nm}^{2}$ for LFP/CB2 and $49 \times 49 \mathrm{~nm}^{2}$ for Gr2. The voxel size in the 3D-data sets was then $27 \times 15 \times 15 \mathrm{~nm}^{3}$ for LFP/CB2 and $14 \times 49 \times 49 \mathrm{~nm}^{3}$ for $\mathrm{Gr} 2$.

Image processing.-Segmentation of the 3D FIB/SEM image data was performed with the program ImageJ (NIH). Due to non-uniform illumination, setting a single threshold for the all micrographs was

Table II. Volumes of collected datasets.

\begin{tabular}{ccc} 
Dataset & Volume (voxels) $\mathrm{X} \times \mathrm{Y} \times \mathrm{Z}$ & Volume $\left(\mu \mathrm{m}^{3}\right) \mathrm{X} \times \mathrm{Y} \times \mathrm{Z}$ \\
\hline LFP/CB2 & $80 \times 850 \times 400$ & $2.2 \times 12.5 \times 5.9$ \\
Gr2 & $328 \times 750 \times 150$ & $4.4 \times 36.6 \times 7.3$
\end{tabular}

not feasible. Therefore the Sauvola algorithm ${ }^{27,28}$ was used to perform local thresholding of the data. The Sauvola algorithm works by dividing the input image into square windows ( $\mathrm{n} \times \mathrm{n}$ pixel) and setting thresholds for each of them based on the mean and standard deviation of the pixel intensities. Visualizations of the $3 \mathrm{D}$ reconstructions of the analyzed data were performed with the program Avizo (FEI).

The particle size distributions (PSD) of LFP/CB2 and Gr2 electrodes were analyzed based on the method introduced by Münch et al. ${ }^{29}$

The tortuosity factor of the pore network $\tau$ was calculated using TauFactor. ${ }^{30}$ The program calculates $\tau$ by finite element modeling of steady state diffusive flow (electrical current/heat transfer/mass transport interchangeably) in a segmented network using normalized potential boundary conditions of 0 and 1 at opposing volume faces. This flow is then related to the flow through a fully open volume.

Electrochemical impedance spectroscopy.-EIS measurements were performed at room temperature in two-electrode configuration for the 26650CC cylindrical cell and in three-electrode setup for the LFP/CB1 and Gr1 electrodes, using a Biologic VMP3 with Pstat/Gstat boards. Two-electrode EIS measurements of the cylindrical cell were obtained in a frequency range from $10 \mathrm{kHz}$ to $1 \mathrm{mHz}(10$ points per decade) at different SOC (state-of-charge) from $0 \%$ to $100 \%$ SOC in the voltage range $2.8-3.6 \mathrm{~V}$. All spectra were measured at OCV after the cell had reached steady state defined by a change $<5 \mathrm{mV} / \mathrm{h}$.

Three-electrode measurements for the LFP/CB1 and Gr1 electrodes were performed in a EL-CELL ECC-Combi, using lithium metal as counter and reference electrodes. The spectra were measured in the frequency range from $100 \mathrm{kHz}$ to $1 \mathrm{mHz}$ (10 points per decade), however for the LFP/CB1 electrode the impedance data recorded above $1 \mathrm{kHz}$ presented an artifact (a "false" semicircle), hard to remove because of the difficulty to scratch LFP from the Al current collector without damaging it, and is therefore treated separately in the supplementary material. The measurements were performed at $\mathrm{OCV}$ after the electrode had reached $0 \%$ and $100 \%$ SOC using a nominal charge/discharge rate of $0.1 \mathrm{C}$, and after reaching steady state defined by a voltage change $<5 \mathrm{mV} / \mathrm{h}$. The voltage cutoff at $0 \%$ and $100 \%$ SOC was defined as $0.5 \mathrm{~V}$ and $0.01 \mathrm{~V}$ for the anode, and $3.0 \mathrm{~V}$ and $3.7 \mathrm{~V}$ for the cathode. 


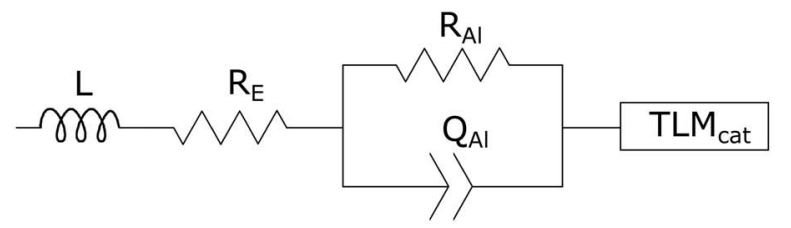

a)
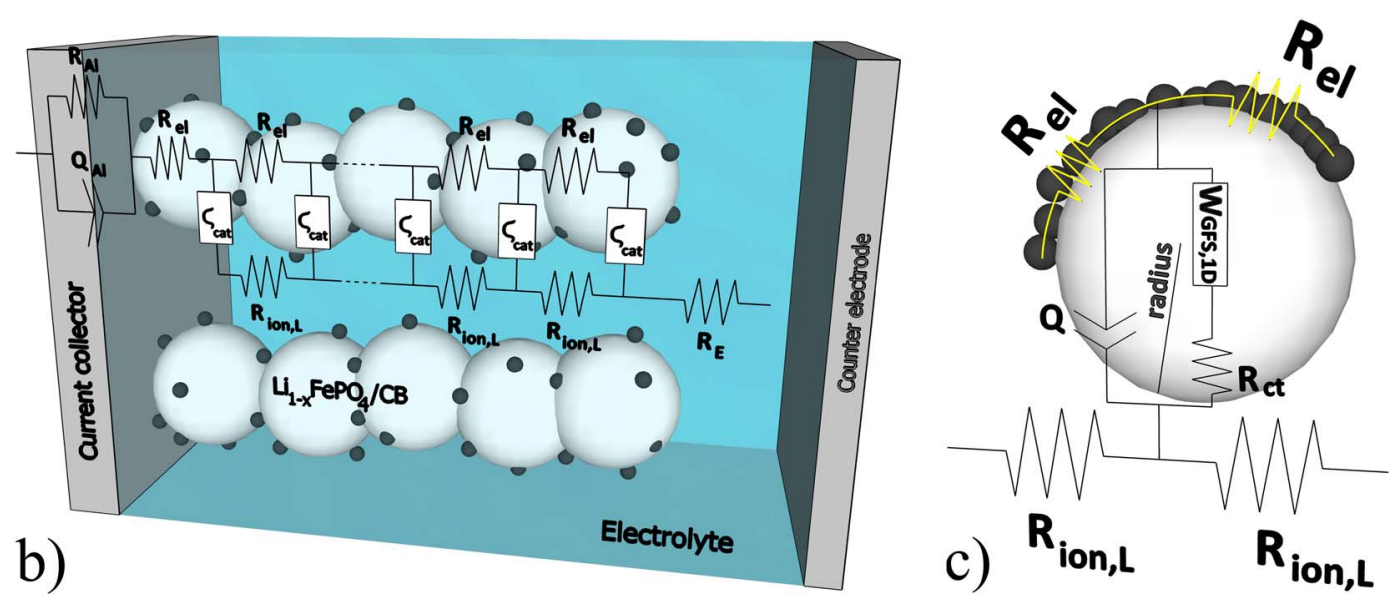

Figure 2. a) Equivalent circuit used to model the impedance spectra measured on the cathode sample, b) Generalized Transmission Line model resembling the element $\mathrm{TLM}_{\text {cat }}$ in a), c) Randles circuit used to model electrode/electrolyte interface with $\mathrm{Li}^{+}$diffusion (Warburg General Finite Space element, $W_{G F S, I D}$ ) within a particle with radius $r$. The Randles circuit resembles the element $\varsigma_{c a t}$ in b). The yellow resistors, $R_{e l}$, in c) model the electronic resistivity along the electron pathway on the surface of the LFP particles, and through the CB network.

Cathode equivalent circuit model.-The impedance results obtained from the LFP/CB1 electrode were modeled using the ECM shown in Fig. 2.

$L_{W}$ is an inductor. The modelled inductance is primarily related to the current leads of the test setup. $R_{E}$ is a resistor modelling the ionic resistance of the electrolyte. $Q_{A l}$ is a constant phase element and $R_{A l}$ is a resistor. $\left(R_{A l} Q_{A l}\right)$, where the brackets indicate a parallel connection between $R_{A l}$ and $Q_{A l}$, models the high-frequency part of the electrode impedance spectra associated with the aluminum/electrode interfacial polarization ${ }^{14,31}$ which is known to be independent on the SOC. The low-frequency part of the electrode impedance spectra is modeled with a generalized TLM for a porous electrode ${ }^{20,32,33}$ (Fig. 2b). The model assumes cylindrical pores with length $L$ filled with the electrolytic solution and oriented perpendicular to the current collector. $R_{\text {ion }, L}$ is the resistance associated with Lithium ions traveling in the pores.

The pores in the electrode are surrounded by carbon coated LFP particles mixed with carbon black particles. $R_{e l}$ is the resistance associated with electrons traveling in the surface coating and CB particles. The equivalent circuit element $\zeta_{c a t}$ models the impedance of the electrode/electrolyte interface and includes the diffusion of lithium ions inside a LFP particle with radius $r$. $\zeta_{\text {cat }}$ consists of a charge transfer resistance $R_{c t}$ in parallel with a constant phase element $Q$ modeling the apparent double layer capacitance of the insertion particles. Additionally $R_{c t}$ is in series with a General Finite Space Warburg element $W_{G F S, I D}$ which models the impedance associated with lithium ion diffusion in the solid particles. More specifically $W_{G F S, I D}$ models a diffusion process along a one-dimensional diffusion path terminated by an impermeable boundary and is chosen for olivine-structure electrode materials $\mathrm{LiMPO}_{4}$ (with $\mathrm{M}=\mathrm{Fe}, \mathrm{Co}, \mathrm{Mn}$ ), since they display a diffusion process along one-dimensional diffusion paths in the crystal lattice. ${ }^{34}$

The single-particle lithiation in an LFP electrode occurs through the $\mathrm{LiFePO}_{4} / \mathrm{FePO}_{4}$ interface moving perpendicular to the [010] direction, ${ }^{35}$ according to an anisotropic two-phase model which appears energetically and kinetically favorable, on the contrary of the isotropic "core-shell" mechanism. ${ }^{35,36}$ Furthermore Allen et al. ${ }^{37}$ determined that the $\mathrm{LiFePO}_{4}$ phase transformation mechanism in a bulk electrode follows a 1D growth mechanisms in $60-70 \mathrm{~nm} \mathrm{LiFePO}_{4}$ particles.
As previously mentioned the electronic resistance is often assumed to be much lower than the ionic resistance of the solution $\left(R_{e l}<<R_{\text {ion }, L}\right)$ resulting in a simplified TLM where $R_{e l}$ is omitted. ${ }^{38,39}$ The generalized TLM ${ }_{\text {cat }}{ }^{20,32,33}$ was used in this study as it reveal non-negligible $R_{e l}$ values. This is further detailed in the Results and Discussion sections.

The impedance of the generalized TLM cat $_{\text {model is: }}$

$$
\begin{aligned}
Z_{T L M}= & \frac{R_{e l} * R_{i o n, L}}{R_{e l}+R_{\text {ion }, L}}\left(L+\frac{2 \lambda_{T L M}}{\sinh \left(L / \lambda_{T L M}\right)}\right) \\
& +\lambda_{T L M} \frac{R_{e l}^{2}+R_{\text {ion }, L}^{2}}{R_{e l}+R_{\text {ion }, L}} \operatorname{coth}\left(L / \lambda_{T L M}\right)
\end{aligned}
$$

With:

$$
\lambda_{T L M}=\sqrt{\varsigma_{\text {cat }} /\left(R_{e l}+R_{\text {ion }, L}\right)}
$$

As mentioned above the electrode/electrolyte interface (Fig. 2c) is modeled with the Randles circuit $\varsigma_{c a t}$ which includes the charge transfer resistance $R_{c t}$, a constant phase element (CPE) $Q$ and the general finite space Warburg element $W_{G F S, I D}$. $W_{G F S, I D}$ has the impedance: $6,8,40$

$$
Z_{W G F S, 1 D}=R_{w} \frac{\operatorname{coth}\left[\left(j \omega \tau_{w}\right)^{n_{w}}\right]}{\left(j \omega \tau_{w}\right)^{n_{w}}}
$$

with the time constant:

$$
\tau_{w}=\frac{r^{2}}{D}
$$

$R_{w}$ is polarization resistance, $r$ is the particle radius, $n_{w}$ is an exponent $\left(0<n_{w}<0.5\right)$ reflecting the degree of non-uniform diffusion, ${ }^{41,42}$ and $D$ is the diffusion coefficient of Lithium ion within $\mathrm{LiFePO}_{4}$.

The effective double layer capacitance $C_{d l}$ is calculated using the expression: ${ }^{43}$

$$
C_{d l}=Q^{1 / n}\left(R_{e}^{-1}+R_{t}^{-1}\right)^{(n-1) / n}
$$

where $Q$ is the CPE, $n$ the exponent of the CPE, $R_{e}$ is the ohmic resistance and $R_{t}$ the generic resistance associated with the CPE.

The units of $R_{c t}$ and $C_{d l}$ in the TLM cat $_{\text {are respectively } \Omega \mathrm{cm}^{3}}$ and $\mathrm{Fcm}^{-3} . R_{c t}$ and $C_{d l}$ values obtained from the modeling can be related to the geometrical electrode area (with the units $\Omega \mathrm{cm}^{2}$ and 

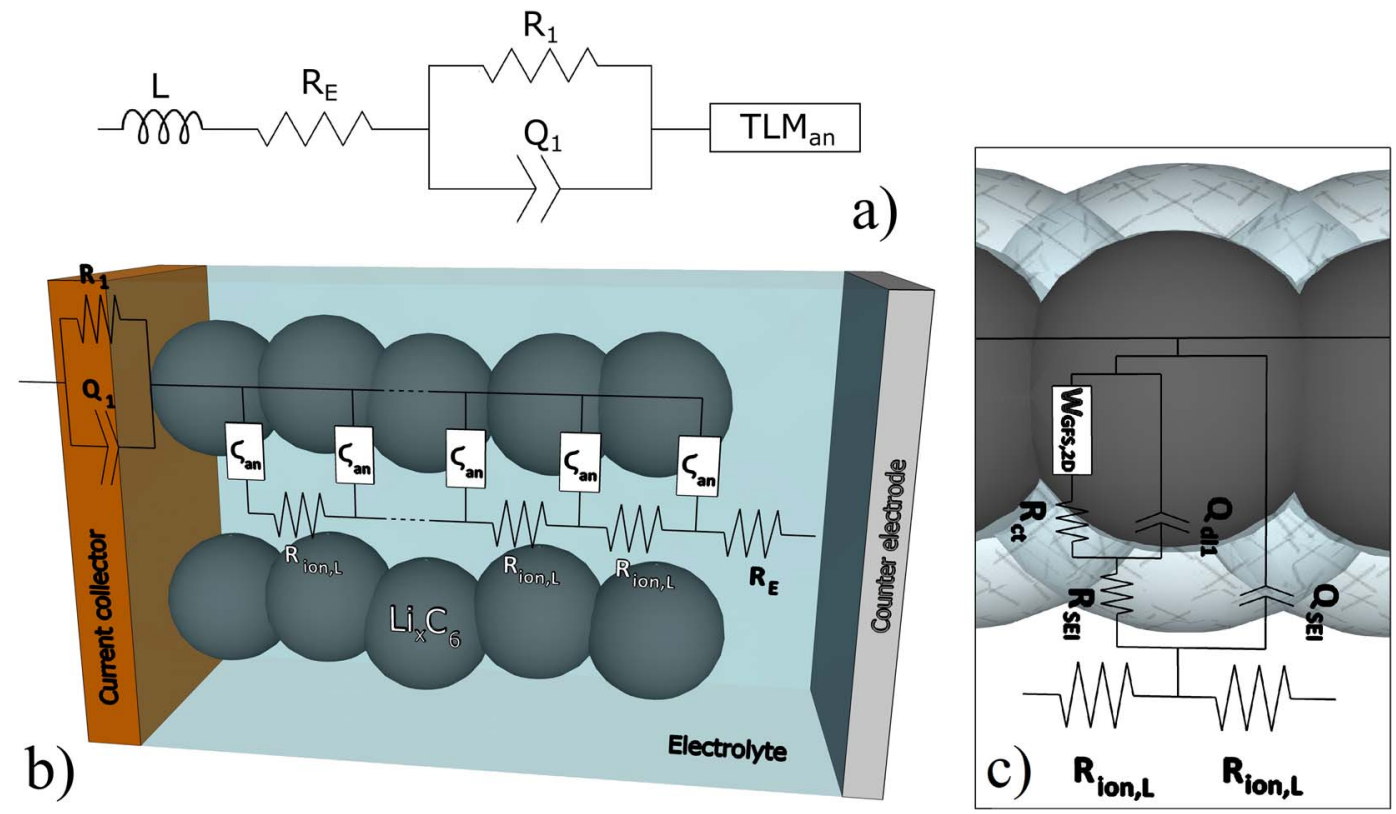

Figure 3. a) Equivalent circuit used to model the anode sample impedance spectra, b) Simplified Transmission Line Model without $R_{e l}$ resembling the element $\mathrm{TLM}_{\mathrm{an}}$ in a), c) Meyers (Case 2) equivalent circuit ${ }^{6}$ used to model electrode/electrolyte interface with $\mathrm{Li}^{+}$diffusion (Warburg Finite Space element, $W_{G F S, 2 D}$ ) within a graphite particle. Meyers circuit resembles the element $\varsigma_{a n}$ in b).

$\mathrm{Fcm}^{-2}$ ) by division and multiplication respectively with the cylindrical pore length $L$ (expressed in $\mathrm{cm}$ ). Here $L$ is set equal to the electrode thickness. The TLM neglects the ion diffusion driven by concentration gradient in the electrolyte phase, but only consider the ion migration, and the structural inhomogeneity. ${ }^{12}$

Anode equivalent circuit model.-The impedance spectra measured on the Gr1 electrode were modeled using an ECM almost similar to the circuit used to model the LFP/CB1 electrode impedance (Fig. 3a). The $R_{E}\left(R_{l} Q_{l}\right)$ elements model the high frequency part of the impedance spectra. $R_{E}$ models the ionic resistance of the electrolyte, while the $R_{l} Q_{l}$ element representing the combined copper current collector/electrode polarization. ${ }^{15}$ Similar to the model for the cathode, the mid- and low-frequency part of the anode spectra are modeled with a TLM for a porous electrode, however here the simplified version is used ${ }^{20,32,33}$ (Fig. 3b), as the condition $R_{\text {el }}<<R_{\text {ion }}$ is valid for the graphite electrode. ${ }^{44-46}$

For a simplified $\mathrm{TLM}_{\mathrm{an}}$ with negligible $R_{e l}$, Equation 1 reduces to:

$$
Z_{T L M}=\lambda_{T L M} R_{i o n, L} \operatorname{coth}\left(L / \lambda_{T L M s}\right)
$$

with:

$$
\lambda_{T L M}=\sqrt{\varsigma_{a n} / R_{\text {ion }, L}}
$$

$\varsigma_{a n}$, is different from $\varsigma_{\text {cat }}$. It is constituted by a resistor $R$ in series with a Randles circuit and in parallel with a constant phase element $Q$ (Fig. $3 \mathrm{c}){ }^{6}$ The element $\zeta_{a n}$ is equivalent to the ECM proposed by Meyers et al. (Case 2) ${ }^{6}$ which describes the impedance response of a porous electrode, covered by a film (in this case the SEI layer illustrated in Fig. $3 c) . R_{S E I}$ models the SEI layer resistance, while the film capacitance $C_{S E I}$ associated with it is calculated from $Q_{S E I}$ according to. ${ }^{43}$ The Randles circuit includes the charge transfer resistance $R_{c t}$, a constant phase element $Q_{d l l}$ and the general finite space Warburg element with a two-dimensional diffusion path, $W_{G F S, 2 D}{ }^{6,8,40}$ with the impedance:

$$
Z_{W G F S, 2 D}=R_{w} \frac{I_{0}\left[\left(j \omega \tau_{w}\right)^{n_{w}}\right]}{\left(j \omega \tau_{w}\right)^{n_{w}} I_{1}\left[\left(j \omega \tau_{w}\right)^{n_{w}}\right]}
$$

where $\mathrm{I}_{0}$ and $\mathrm{I}_{1}$ are modified zero- and first-order Bessel functions of the first kind.

Here a 2D Warburg finite space element with cylindrical geometry is used. ${ }^{15,47}$ This geometry describes a diffusion along the radial axis, usually associated with layered-structure electrodes, such as graphite, which allow two-dimensional lithium insertion. ${ }^{48}$

Simulations of the impedance of the full cell/electrode/individual circuit elements, and complex nonlinear least squares fitting of the equivalent circuit models to the data was performed using software programmed in Python ${ }^{49}$ which relies on the scientific Python stack, ${ }^{50-52}$ and for the 1D/2D elements the library mpmath was used to provide higher precision complex floating-point arithmetic. ${ }^{53}$

Tortuosity estimation from TLMs.-The ionic resistivity in the infiltrated pore with length $L, R_{\text {ion }, L}[\Omega \mathrm{cm}]$ calculated from the TLMs is correlated to the effective electrode pore tortuosity $\tau_{e l}$ through the equation:

$$
\tau_{e l}=\sigma_{i o n} R_{i o n, L} \varepsilon_{e l}
$$

where $\sigma_{i o n}$ is the bulk ionic conductivity with the unit $\left[\mathrm{Scm}^{-1}\right]$, and $\varepsilon_{e l}$ is the electrode porosity. ${ }^{15}$ In our modeling work we used $\sigma_{i o n}=$ $1.18 \cdot 10^{-2} \mathrm{Scm}^{-1}$, which is an average of the values reported for $1 \mathrm{M}$ $\mathrm{LiPF}_{6}$ in 1:1 EC/DMC (the electrolyte used for the single electrode tests) by Lombardo et al., ${ }^{45}$ and Porion et al. ${ }^{46}$

\section{Results}

FIB/SEM tomography. - Figures 4 and 5 show respectively crosssection lateral E-T images after FIB milling of the LFP/CB2 and the $\mathrm{Gr} 2$ electrode. In the top region of the images it is possible to observe a very bright region, which is the sample surface after polishing. Looking inside the milled samples, current collector/electrode and electrode/electrolyte interfaces can be distinguished for both samples. Guidelines are shown in Fig. 4a to indicate how the interfaces extend into the sample. From Fig. 4a the cathode thickness is estimated to 65 $\mu \mathrm{m}$. Fig. $4 \mathrm{~b}$ show a higher resolution image of the electrode/electrolyte interface. Inside the electrode, three different phases are distinguished: light gray $\mathrm{LiFePO}_{4}$ particles, dark gray pores (infiltrated with silicon resin) and black $\mathrm{CB}$ particles. On the right side of the SEM image (Fig. 4a), where the electrolyte is supposed to be, there is a dark gray bulk of silicon resin with some LFP and CB particles, which probably detached during sample preparation.

Inside the Gr2 electrode (Fig. 5), only two phases can be distinguished: dark graphite particles and gray pores infiltrated with silicon 


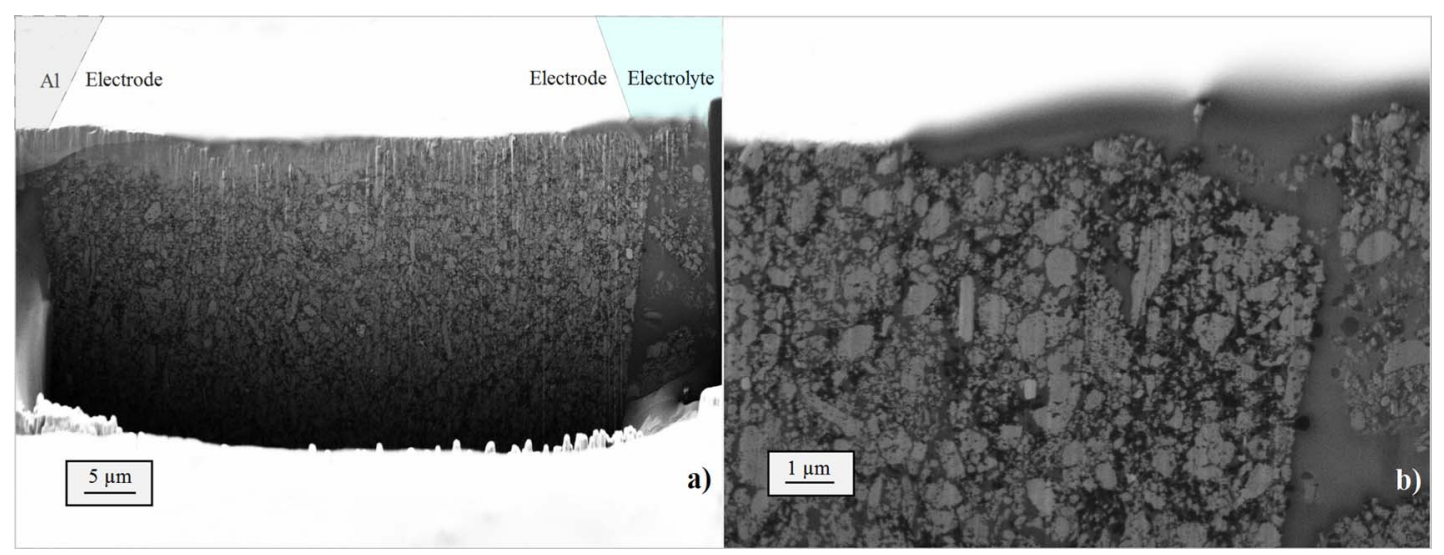

Figure 4. a) FIB/SEM cross-section image of the LFP/CB2 electrode, collected with lateral E-T detector. On the top, guidelines are shown to distinguish Al/Electrode and Electrode/Electrolyte interfaces, b) High resolution FIB/SEM cross-section image of Electrode/Electrolyte interface, used for 3D reconstruction and PSD.

resin. On the left side the copper/electrode interface is present, while on the right side the electrode/electrolyte interface is found. From the figure the electrode thickness is estimated to $35 \mu \mathrm{m}$. The darker gray bulk on the right is the epoxy resin, used for sample preparation, which yields a different brightness in the SEM images than silicon resin. The red rectangle indicates the region segmented for $3 \mathrm{D}$ reconstruction and PSD analysis.

Figure 6 shows a 3D reconstruction of the LFP/CB2 electrode/electrolyte interface and of the $\mathrm{Gr} 2$ electrode. In the cathode $3 \mathrm{D}$ reconstruction (Fig. 6a) the gray phase is the $\mathrm{LiFePO}_{4}$, the black phase is the $\mathrm{CB}$ additive network, while the electrolyte infiltrated pores are transparent blue. All phases (separated in Figs. 7a, 7b, 7c) seem quite homogeneously distributed. In the anode 3D reconstruction (Fig. $6 b)$ the orange region represents the copper current collector, the black particles are graphite agglomerates and the transparent blue region is the pores network infiltrated with the electrolyte. The two phases in the Gr2 electrode are shown in Figs. 7d, 7e.

Figs. 8a, 8b show respectively the PSD distributions for the three phases in the LFP/CB2 electrode and for the two phases in the $\mathrm{Gr} 2$ electrode. The average particle size for the active materials, $\mathrm{Li}_{1-\mathrm{x}} \mathrm{FePO}_{4}$ and $\mathrm{Li}_{\mathrm{x}} \mathrm{C}_{6}$, is respectively $76 \mathrm{~nm}$ and $1096 \mathrm{~nm}$. These values are implemented in the TLMs used to model the impedance

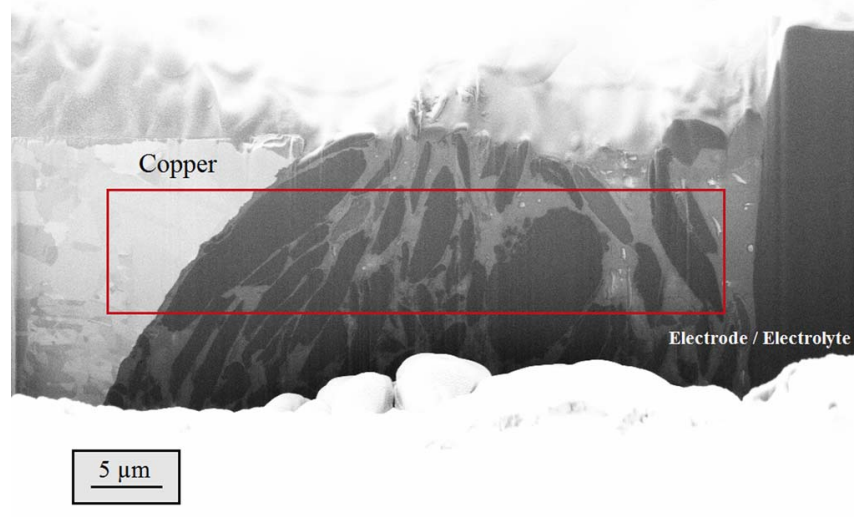

Figure 5. FIB/SEM cross-section image of the Gr2 electrode, obtained with a lateral E-T detector. The copper current collector is seen in the left part of the figure and the Electrode/Electrolyte interface, in the right part. The red rectangle indicates the region segmented for $3 \mathrm{D}$ reconstruction and PSD analysis. spectra measured on the cylindrical cell and the electrode samples. Volume fraction values for all the phases are shown in Table III.

Fig. 9 shows the normalized 3D potential maps used in the pore tortuosity factor calculations. The calculated cathode pore tortuosity factor is 5.9, while the anode pore tortuosity factor is 24.8. From Fig. $9 \mathrm{~b}$ it is evident that the volume analyzed for the anode is too small to be representative due to the big graphite particles and the single narrow pathway that connects the two sides of the volume. Thus the accuracy of the calculated anode tortuosity factor is very low. The tortuosity factor for a larger representative part of the electrode is expected to be significantly smaller.

Galvanostatic cycling with potentiostatic limitation (GCPL).The 26650CC cell was cycled between $2.8-3.6 \mathrm{~V}$ as suggested from the commercial supplier, at a nominal C-rate of $0.1 \mathrm{C}$. The charge/discharge curve for 26650CC is shown in Fig. 10a (black line).

Figs. $10 \mathrm{~b}$ and $10 \mathrm{c}$ show respectively the charge/discharge curves for the LFP/CB1 and Gr1 electrodes. The LFP/CB1 electrode is cycled between $3.0-3.7 \mathrm{~V}$ with a constant current of $330 \mu \mathrm{A}$, corresponding to a $\mathrm{C}$-rate of $0.1 .^{\mathrm{a}}$ The charge/discharge curve shows a typical flat plateau of a $\mathrm{Li}_{1-\mathrm{x}} \mathrm{FePO}_{4}$ electrode at around $3.45 \mathrm{~V}$ (with $0 \leq \mathrm{x} \leq 1$ ). Note that the normalized charge/discharge capacity of LFP/CB1 is $10 \%$ higher than the normalized capacity of $26650 \mathrm{CC}$. This matches with the typical $10 \%$ lithium loss for SEI layer formation on the graphite surfaces in the anode during the first charge/discharge cycle of the 26650CC. The Gr1 electrode was cycled between $0.01 \mathrm{~V}$ and 0.5 $\mathrm{V}$, also at $330 \mu \mathrm{A}$ (Fig. 10c) showing typical $\mathrm{Li}^{+}$ion intercalation steps (with $0 \leq \mathrm{x} \leq 1$ ). Note that the normalized charge/discharge curve of $26650 \mathrm{CC}$ resembles well the voltage difference between the LFP/CB1 and Gr1 normalized charge/discharge curves, as shown by the green curve in Fig. 10a. This voltage difference does not match exactly the $0 \%$ and $100 \%$ SOC voltage cutoff for the $26650 \mathrm{CC}$ charge/discharge curves. This may again be explained by either the $10 \%$ capacity difference of the LFP/CB1 electrode.

To simplify the nomenclature, " $\mathrm{LiFePO}_{4}$ " refers to the $\mathrm{Li}_{1-\mathrm{x}} \mathrm{FePO}_{4}$ electrode at $0 \% \mathrm{SOC}$, and " $\mathrm{FePO}_{4}$ " denotes the $\mathrm{Li}_{1-\mathrm{x}} \mathrm{FePO}_{4}$ electrode at $100 \%$ SOC.

EIS modelling of $\mathrm{Li}_{1-x} \mathrm{FePO}_{4}$ electrode (three-electrode configuration).-Fig. 11 shows the area-normalized ${ }^{b}$ EIS spectra measured for the LFP/CB1 electrode in the discharged (Figs. 11a, $11 \mathrm{~b}, 11 \mathrm{c}, 11 \mathrm{~d}$ ) and charged state (Figs. 11e, 11f, 11g, 11h). Figs. 11a, $11 \mathrm{c}$ show respectively a Nyquist and a Bode plot of the EIS spectrum

${ }^{a}$ The $26650 \mathrm{CC}$ cell has a nominal capacity of $2.5 \mathrm{Ah}$ and an area of $1950 \mathrm{~cm}^{2}$ : this corresponds to a capacity of $1.282 \mathrm{mAh} / \mathrm{cm}^{2}$. The area of the electrode coins used here was $2.55 \mathrm{~cm}^{2}$ (18 mm diameter) yielding a capacity of $3.27 \mathrm{mAh}$

${ }^{b}$ Normalized to the geometrical surface area $2.55 \mathrm{~cm}^{2}$ 


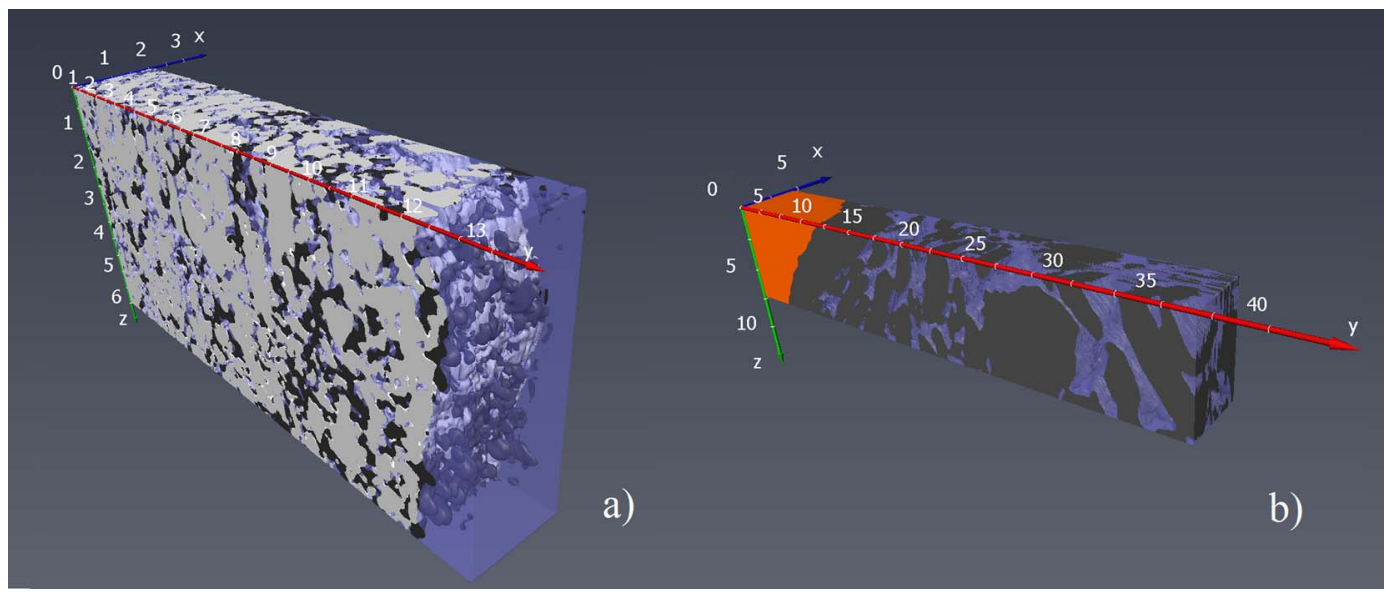

Figure 6. 3D reconstructions of a) LFP/CB2 electrode/electrolyte (transparent blue) interface and b) Gr2 electrode/Cu current collector (orange) interface. The scale bar units are $[\mu \mathrm{m}]$.

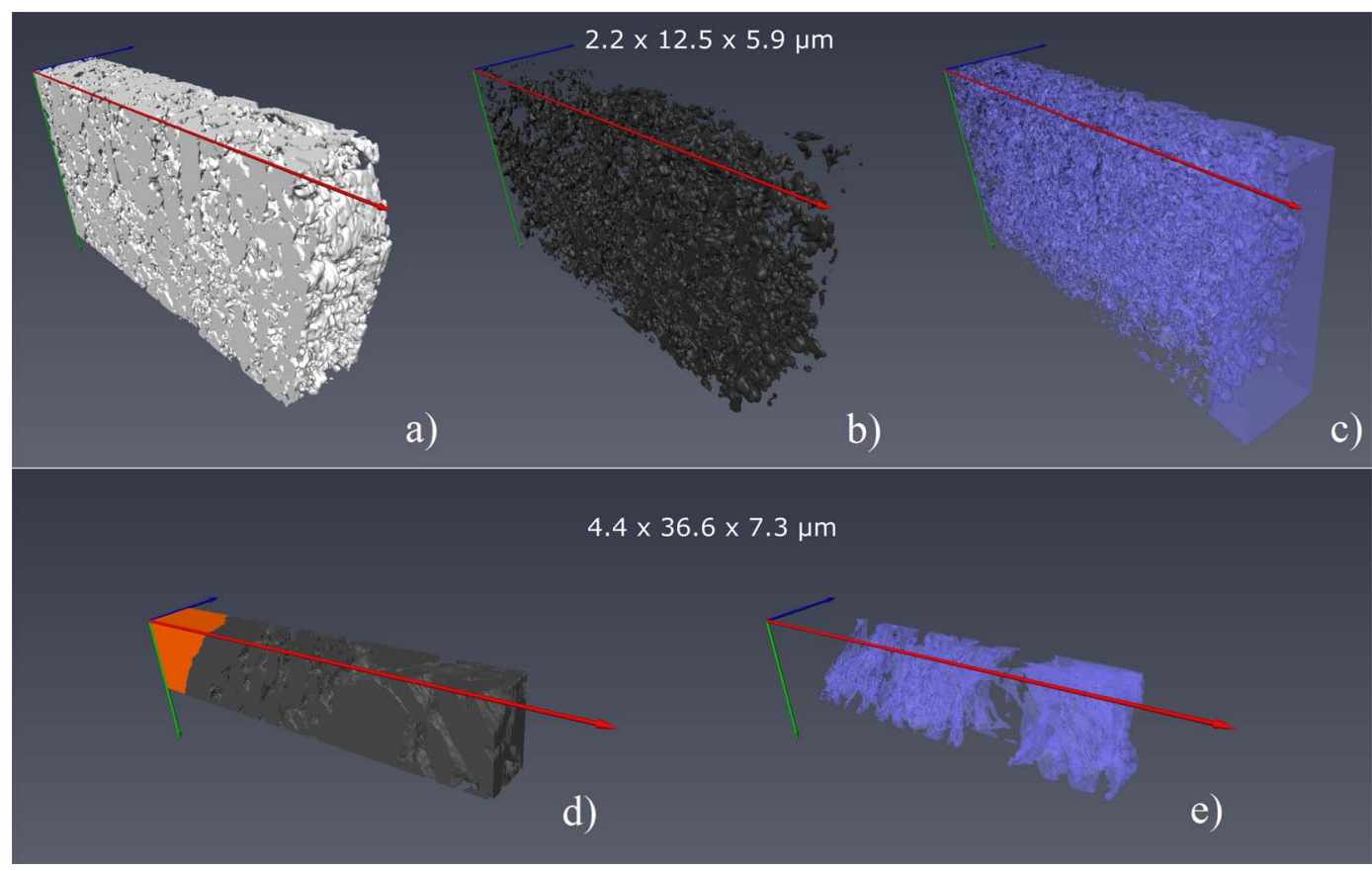

Figure 7. 3D reconstruction of a) LFP, b) CB and c) pore networks in the LFP/CB2 electrode. 3D reconstruction of d) Graphite and e) pore networks in the Gr2 electrode.
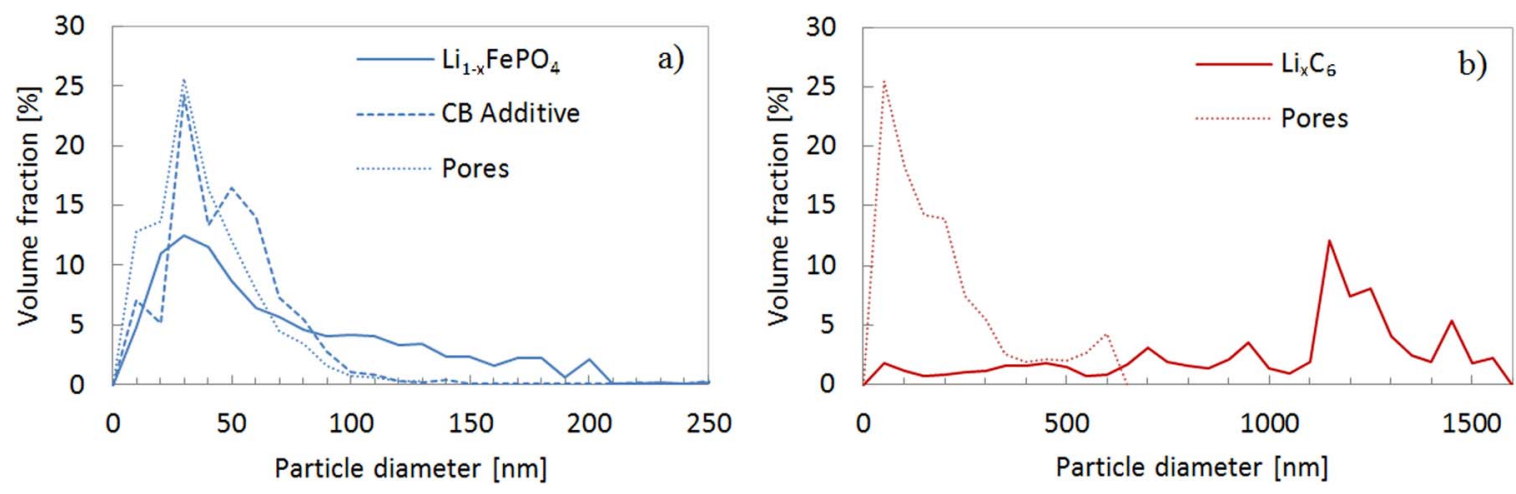

Figure 8. Particle size distributions for a) LFP/CB2 and b) Gr2 electrodes. 
Table III. Volume fraction and average size for the different phases.

LFP/CB2

$\mathrm{Gr} 2$

\begin{tabular}{ccccc}
\cline { 2 - 3 } Phase & Volume Fraction [\%] & Avg. size [nm] & Volume Fraction [\%] & 70 \\
\hline Active Material & 58 & 76 & - & 1096 \\
CB Additive & 17 & 49 & - & 30
\end{tabular}

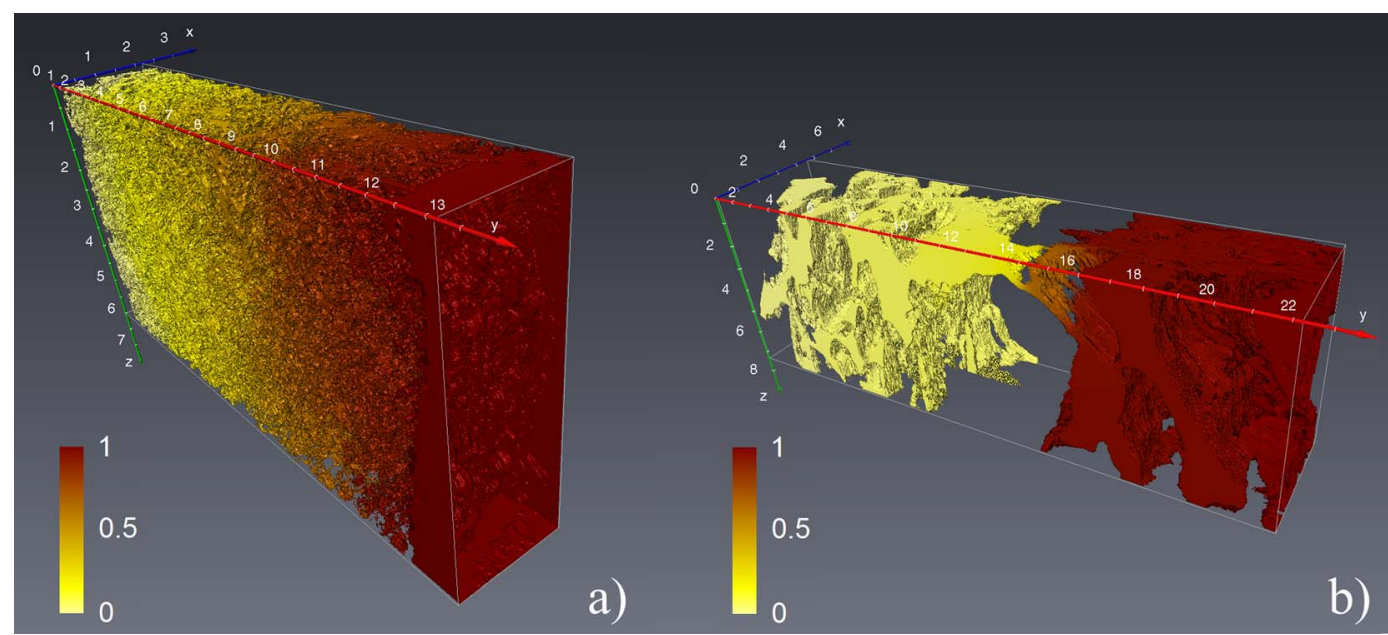

Figure 9. 3D surface renderings of the normalized potential maps used in the tortuosity factor calculations by TauFactor. ${ }^{30}$ a) $\mathrm{LFP} / \mathrm{CB} 2 \mathrm{electrode}$ b) Gr2 electrode.

measured at $\mathrm{OCV}$ after discharging to $3.0 \mathrm{~V}$ and relaxation. Figs. 11e, $11 \mathrm{~g}$ show a Nyquist and Bode plot of the EIS spectrum measured at OCV after charging the LFP electrode to $3.7 \mathrm{~V}$ and subsequent relaxation. Figs. 11b, 11f and the insets in Figs. 11c, 11g show a zoomed view of the high frequency regions of the spectra. The measured data is modeled (black lines) using the ECM described in Cathode Equivalent Circuit Model section highlighting two parts of model: The $\left(R_{A l} Q_{A l}\right)$
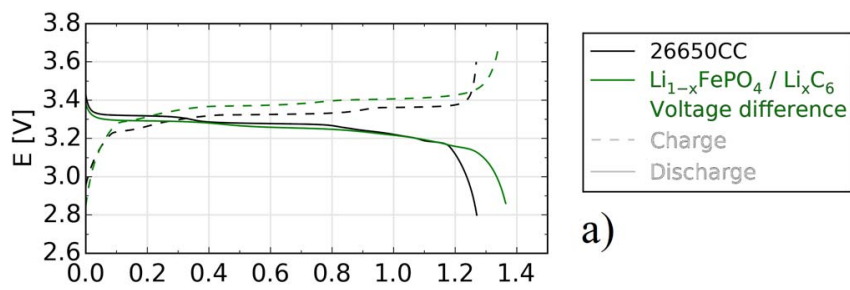

a)
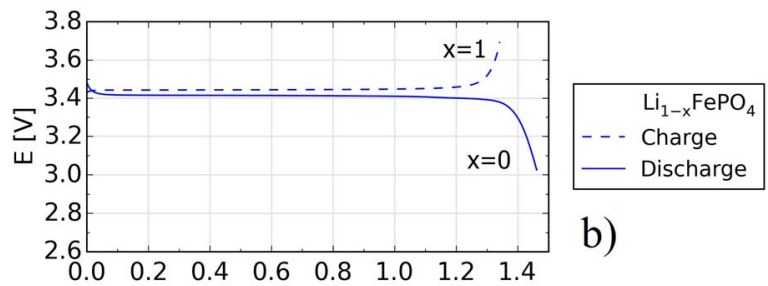

b)
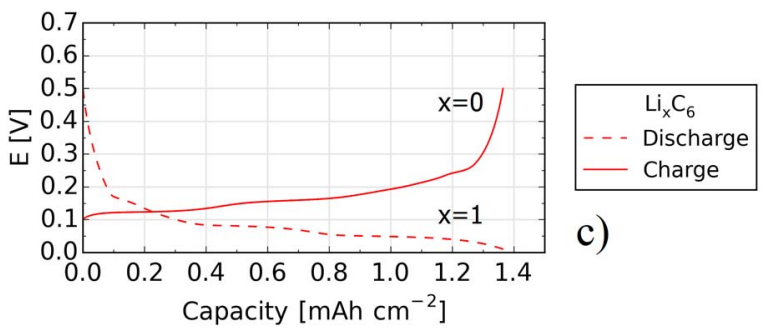

c)

Figure 10. Charge/Discharge curves measured on the a) $26650 \mathrm{CC}$ cell, b) LFP/CB1 cathode and c) Gr1 anode.

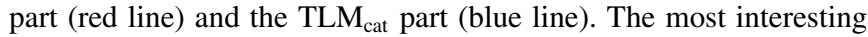
part of the modelling results are presented in Table IV and discussed in Discussion section. All the modeling results are presented in the supplementary information in Table S1. The relative residuals between measured and modeled spectra are shown in Figs. 11d, 11h.

Equivalent circuit modelling of $\mathrm{Li}_{x} \mathrm{C}_{6}$ electrode (three-electrode configuration).-Fig. 12 shows the area-normalized EIS spectra measured for Gr1 in the delithiated (Figs. 12a, 12b, 12c, 12d) and lithiated form (Figs. 12e, 12f, 12g). Figs. 12a, 12c show Nyquist and Bode plot of the Gr1 spectrum measured at OCV after charging the electrode to $0.5 \mathrm{~V}$ followed by relaxation. Figs. 12e, 12f show Nyquist and Bode plots of the Gr1 spectrum measured after discharging the electrode to $0.01 \mathrm{~V}$ and after relaxation. Fig. 12b and the inset in Fig. 12c show a zoomed view of the high frequency region of the spectrum.

The measured data is modeled (black lines) using the ECM described in Anode Equivalent Circuit Model section highlighting two parts of model: The $\left(R_{l} Q_{l}\right)$ part (green line) and the $\mathrm{TLM}_{\mathrm{an}}$ part (blue line). The most interesting part of the modelling results are presented in Table V and discussed in Discussion section. All the modeling results are reported in Table S2 in the supplementary information. The relative residuals between measured and modeled spectra are shown in Figs. 12d, 12g.

Equivalent circuit modelling of 26650CC (two-electrode configuration).--Impedance spectra obtained on the $26650 \mathrm{CC}$ were recorded at different SOC in charging and discharging mode. Fig. 13 shows the area-normalized EIS spectra measured for 26650CC at different SOC (dots), with the simulated curves corresponding to the best model fit (solid lines) for each spectrum. A full description of the equivalent circuit used to model the spectra and the fitting results are provided in Equivalent Circuit Description and EIS spectra fitting sections.

\section{Discussion}

Cathode impedance modelling: three-electrode configuration.-The Nyquist plots of $\mathrm{LiFePO}_{4}$ and $\mathrm{FePO}_{4}$ (Figs. 11b, 11f) consist of a small semicircle in the high frequency region between 


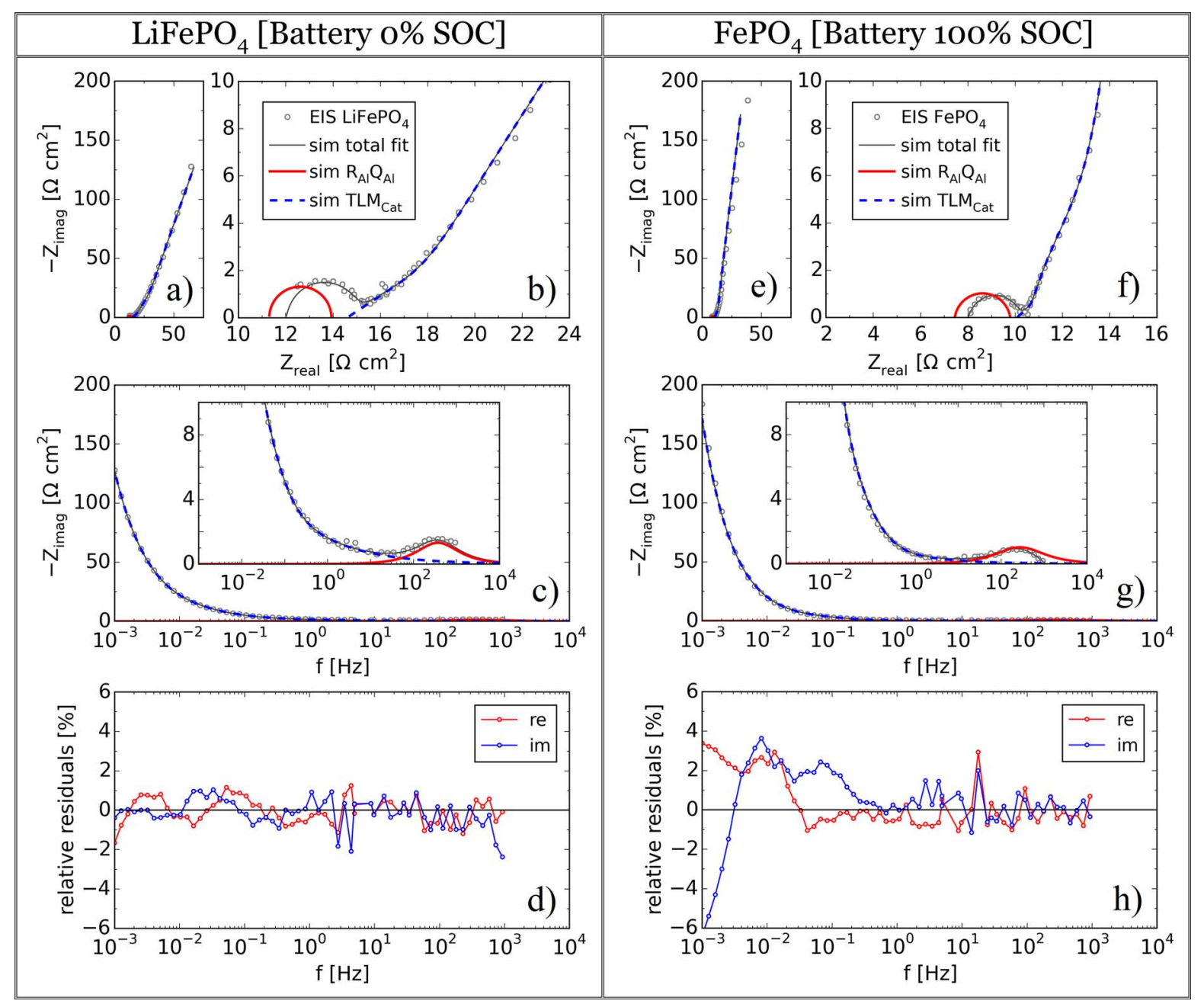

Figure 11. a) Nyquist plot, b) Zoomed view, and c) Bode plot of the $\mathrm{Li}_{1-\mathrm{x}} \mathrm{FePO}_{4}$ electrode at $0 \% \mathrm{SOC}(\mathrm{x}=0)$. e) Nyquist, f) Zoomed view, and g) Bode plot of the $\mathrm{Li}_{1-\mathrm{x}} \mathrm{FePO}_{4}$ electrode at $100 \% \mathrm{SOC}(\mathrm{x}=1)$. d) and $\mathrm{h}$ ) show relative residuals between model fit and measured data. Inset in $\left.\mathrm{c}\right)$ and $\left.\mathrm{g}\right)$ shows rescaled Bode plots to highlight the high-frequency part of the spectra.

$1 \mathrm{kHz}-100 \mathrm{~Hz}$ and a low frequency branch characterized by an almost vertical tail in the charged state, and a less vertical tail in the discharged state.

$R_{A l} Q_{A l}$ models the contact resistance between the Aluminum foil and the $\mathrm{Li}_{1-\mathrm{x}} \mathrm{FePO}_{4} / \mathrm{CB}$ network. From Table IV it is seen that the $R_{A l}$ values change very little for the two different SOCs, in agreement with literature. ${ }^{14}$

The high frequency side of the semicircle intersects with the $\mathrm{x}$-axis at $12.0 \Omega \mathrm{cm}^{2}$ and $8.0 \Omega \mathrm{cm}^{2}$ for $\mathrm{LiFePO}_{4}$ and $\mathrm{FePO}_{4}$ respectively. However, because of the inductance and in particular due to the nonnegligible electronic resistance $\left(R_{e l}\right)$, the electrolyte resistance $\left(R_{E}\right)$ values are somewhat smaller: $11.2 \Omega \mathrm{cm}^{2}$ and $7.4 \Omega \mathrm{cm}^{2}$, respectively as presented in Table $\mathrm{S} 1$. When $R_{e l}$ is non-negligible relative to $R_{i o n, L}$ the generalized $\mathrm{TLM}_{\mathrm{cat}}$ features a small ohmic contribution which shifts the starting point of the red semi-circle to the left in the Nyquist plot, Figs. 11b, 11f. If this ohmic contribution was placed on the left side of the red semi-circle it would be easier to see how the semi-circle contributes to the total spectrum, however the semi-circle is deliberately plotted with the $\mathrm{TLM}_{\text {cat }}$ shifted to the right side to highlight the small ohmic contribution from the TLM $\mathrm{Tat}_{\text {cat }}$ as this contribution also affects the value of $R_{E}$. The value of $R_{E}$ is not expected to change with SOC and the change is possibly related to measurement uncertainties; the impedance measured above $1 \mathrm{kHz}$, as described before, presented an artifact and was therefore removed before the impedance was modeled. A "false" semicircle was observed and related to some effect of the non-complete scratching of active materials from the Al current collector. It was not observed on the graphite electrode where the active material was much softer and easier to scratch off.

Table IV. Results from EIS fitting of $\mathrm{Li}_{1-\mathrm{F}} \mathrm{FePO}_{4}$ electrode.

Generalized transmission line

\begin{tabular}{|c|c|c|c|c|c|c|c|}
\hline & \multicolumn{2}{|c|}{$\mathrm{R}_{\mathrm{Al}} \mathrm{Q}_{\mathrm{Al}}$ element } & \multicolumn{3}{|c|}{ Randles element } & \multirow{2}{*}{$\begin{array}{c}\text { Pore } \\
R_{\text {ion }, L}(\Omega \mathrm{cm})\end{array}$} & \multirow{2}{*}{$\begin{array}{l}\text { Electrode } \\
R_{e l}(\Omega \mathrm{cm})\end{array}$} \\
\hline & $R_{A l}\left(\Omega \mathrm{cm}^{2}\right)$ & $C_{A l}\left(m F m^{-2}\right)$ & $R_{c t}\left(\Omega \mathrm{cm}^{2}\right)$ & $C_{d l}\left(F_{c m}^{-2}\right)$ & $D\left(\mathrm{~cm}^{2} \mathrm{~s}^{-1}\right)$ & & \\
\hline $\mathrm{LiFePO}_{4}$ & 2.7 & 0.16 & 34.9 & 0.51 & $4.4 \cdot 10^{-13}$ & 1596 & 109 \\
\hline $\mathrm{FePO}_{4}$ & 2.3 & 0.24 & 8.2 & 0.48 & $1.8 \cdot 10^{-12}$ & 395 & 54 \\
\hline
\end{tabular}




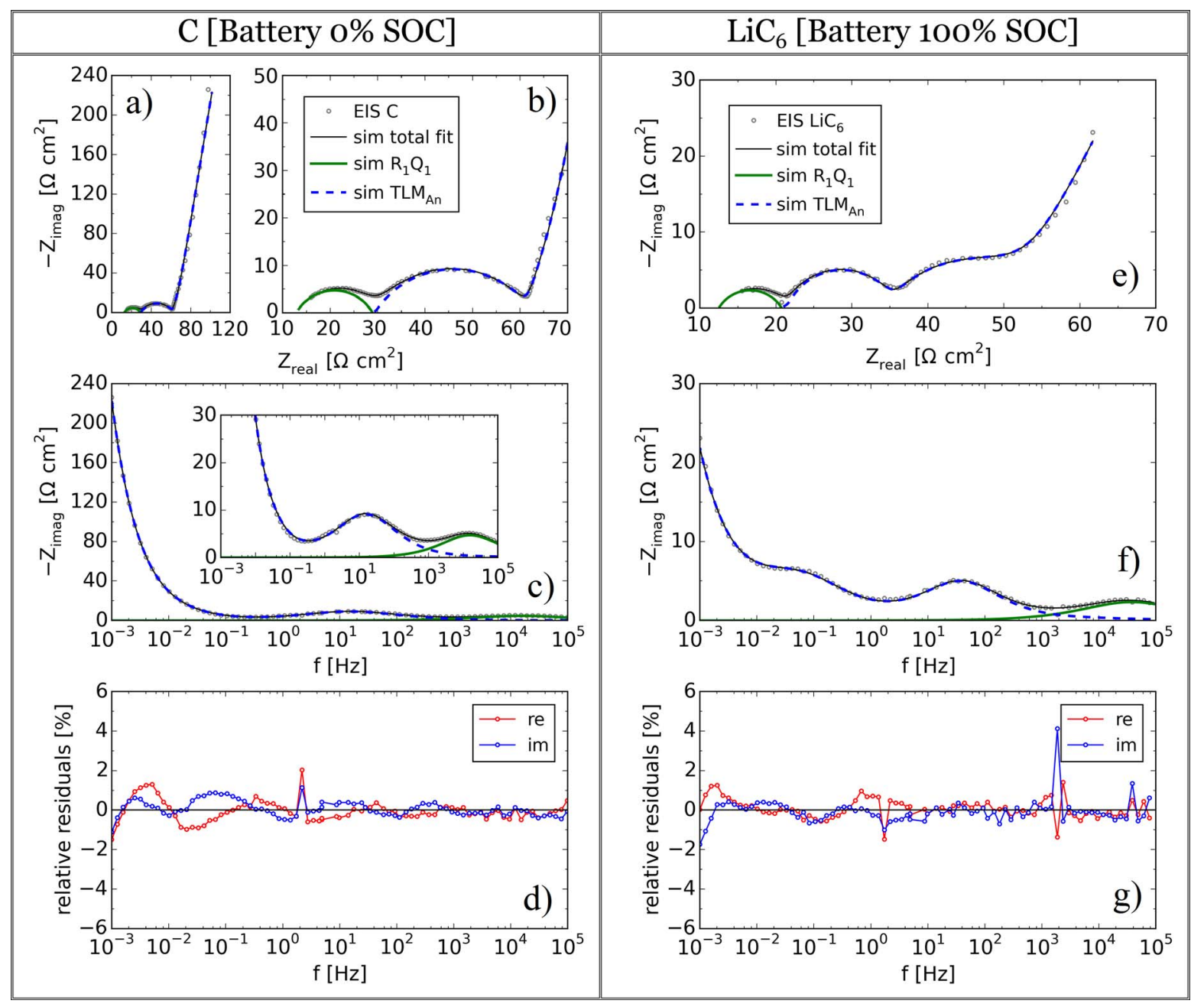

Figure 12. a) Nyquist, b) Zoomed view, and c) Bode plot of the $\mathrm{Li}_{\mathrm{x}} \mathrm{C}_{6}$ electrode at $0 \% \mathrm{SOC}(\mathrm{x}=0)$. (e) Nyquist, and f) Bode plot of the $\mathrm{Li}_{\mathrm{x}} \mathrm{C}_{6}$ electrode at $100 \%$ SOC $(\mathrm{x}=1)$. d) and $\mathrm{g})$ show relative residuals between model fit and measured data. Inset in $\mathrm{c})$ and $\mathrm{f}$ ) shows rescaled Bode plots to highlight the high-frequency part of the spectra.

The values used in the $\mathrm{TLM}_{\mathrm{cat}}$ for the electrode thickness $L$ and the particle radius $r$ are $65 \mu \mathrm{m}$ and $38 \mathrm{~nm}$, respectively. These values were obtained from the presented FIB/SEM analysis and PSD calculation.

Diffusion of $\mathrm{Li}^{+}$ions through the liquid electrolyte in the electrode pores results in a $45^{\circ}$ slope in the beginning of the $\operatorname{TLM}_{\text {cat }}$ curve. The length of the part of the $\mathrm{TLM}_{\text {cat }}$ curve resembling a line with a $45^{\circ}$ slope is determined by $R_{i o n, L}$ and the thickness of the electrode. Once a $\mathrm{Li}^{+}$ion has traveled through a pore and reached a coated LFP particle, it will adsorb (insert) and diffuse (together with an electron, forming a polaron ${ }^{54}$ ) into the bulk of the LFP particle. This is modelled by $\varsigma_{\text {cat }}$ and results in a semicircle followed by a $45^{\circ}$ curve terminating in a capacitive-like response as seen in Figs. 11a, 11b, 11e, and 11f. The semicircle is the result of charge transfer resistance, $R_{c t}$, of $\mathrm{Li}^{+}$ at the particle/electrolyte interface and double layer capacitance $C_{d l}$, in parallel, calculated from the CPE used to model it. The $45^{\circ}$ line followed by a capacitive-like curve corresponds to the finite space Warburg element $W_{G F S, I D}$ which represents diffusion of $\mathrm{Li}^{+}$ions in the electrode network, until all the active material is lithiated/delithiated.

The fitted values from the TLM $\mathrm{T}_{\text {cat }}$ show that $R_{e l}$ is not negligible compared to $R_{i o n, L}$. Both resistances in the pore and the electrode are observed to decrease when the electrode is charged and mainly consists of $\mathrm{FePO}_{4} \cdot \mathrm{Li}_{1-\mathrm{x}} \mathrm{FePO}_{4}$ particles are known to be subjected to expansion/contraction with cycling. When the electrode is completely delithiated, $\mathrm{FePO}_{4}$ particles have a small volume and consequently the pore volume have increased, resulting in a lower $R_{i o n, L} . R_{e l}$ depends on the CB network tortuosity which changes due to particle movements during lithiation/delithiation process. $R_{c t}$ is observed to be significantly lower at $100 \%$ SOC, in agreement with literature. ${ }^{14,55-57}$

Table V. Results from EIS fitting of $\mathrm{Li}_{\mathrm{x}} \mathrm{C}_{6}$ electrode.

Simplified transmission line

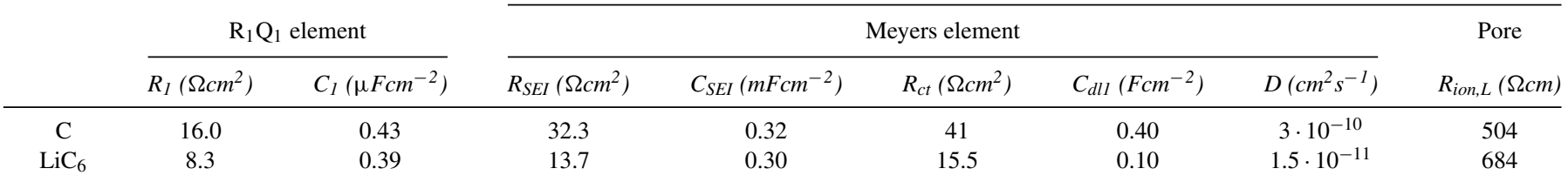



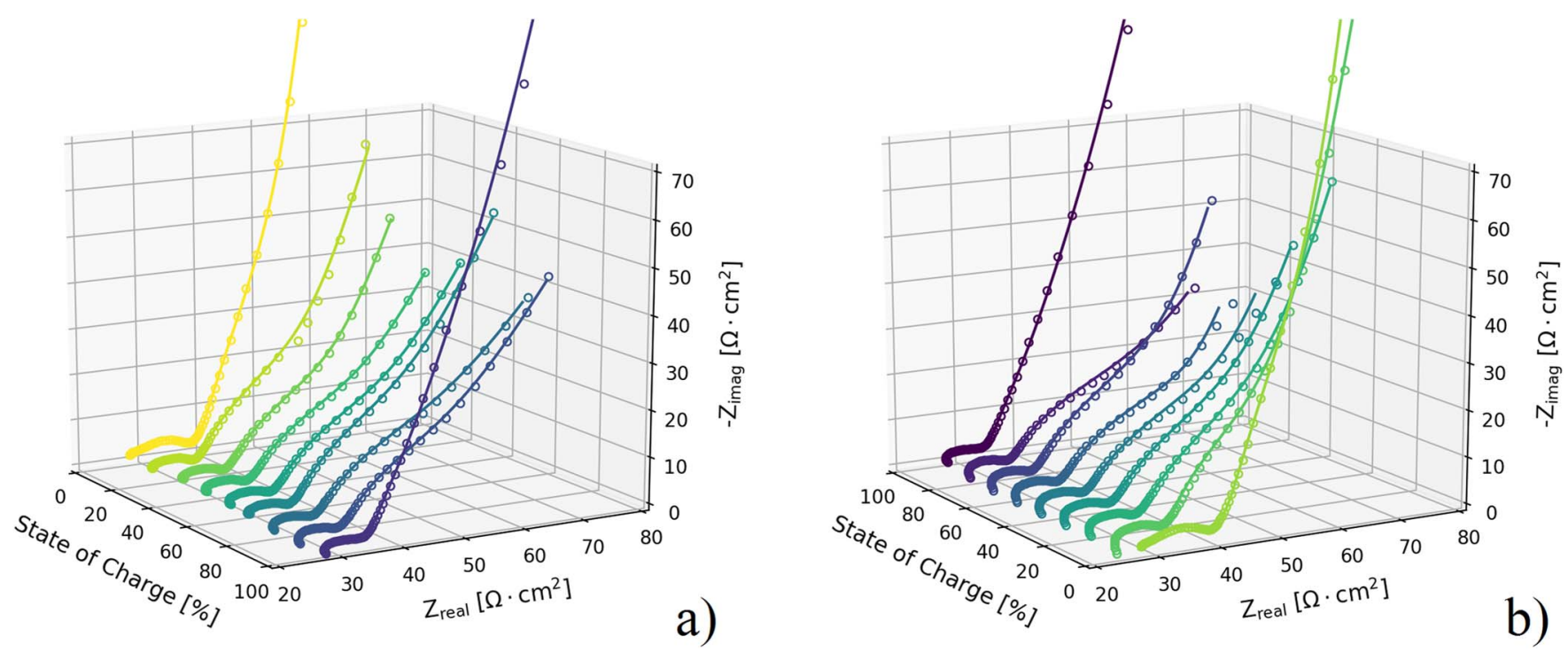

Figure 13. Nyquist plots of $26650 \mathrm{CC}$ at different SOC, measured in a) charging and b) discharging mode. Solid lines represent the best fit to the measured data (dots) using the model presented and discussed in Discussion section.

Anode impedance modelling: three-electrode configuration.The Nyquist plot of the impedance spectra for Gr1 (Figs. 12a, 12b, and $12 \mathrm{e}$ ) consists of a small semicircle in the high frequency region, between $100 \mathrm{kHz}-10 \mathrm{kHz}$, a second bigger semicircle in the midfrequency range $(100 \mathrm{~Hz}-10 \mathrm{~Hz})$ and - similar to the LFP/CB1 electrode - a low frequency branch (at frequencies lower than $1 \mathrm{~Hz}$ ) characterized by an almost vertical tail, in the charged state, and a diffusive tail in the discharged state. Parameter values obtained from the modelling are given in Table $\mathrm{V}$.

The high frequency side of the impedance curve does not intersect with the $\mathrm{x}$-axis, so the electrolyte resistance $\left(R_{E}\right)$ is obtained from the modeling and was $12.9 \Omega \mathrm{cm}^{2}$ and $12.5 \Omega \mathrm{cm}^{2}$ for $\mathrm{C}$ and $\mathrm{LiC}_{6}$ respectively, see Table $\mathrm{S} 2$. The first semicircle $\left(R_{l} Q_{l}\right)$ observed at high frequencies (higher than $10 \mathrm{kHz}$ ) can be assigned to the interface between the copper current collector and/or the porous graphite anode or the graphite particle/particle contact resistance, ${ }^{15}$ with $R_{l}$ and $Q_{l}$ representing contact resistance and the double layer capacitance at these interfaces, respectfully. The value obtained for $R_{l}$ is observed to be significantly lower at $100 \%$ SOC than at $0 \%$ SOC. The double layer capacitance at this interface $C_{l}$ is around three orders of magnitude smaller than $C_{A l}$ at the cathode (Table IV). This is probably due to the smaller specific surface area in the anode: the average graphite particle diameter is around $1.1 \mu \mathrm{m}$, while $\mathrm{CB}$ grains in the positive electrode are equal to $49 \mathrm{~nm}$.

The second semicircle at $100 \mathrm{~Hz}-10 \mathrm{~Hz}$ is related to the SEI layer formed around each graphite particle and is modelled by the elements $R_{S E I}$ and $Q_{S E I}$ (placed in parallel) which are part of $\varsigma_{a n}$ inside the Simplified Transmission Line Model $\left(\mathrm{TLM}_{\mathrm{an}}\right)$ for a porous electrode. ${ }^{6,8,20,32,33,40}$ The low frequency branch $(<1 \mathrm{~Hz})$ is associated with the Randles element of $\varsigma_{a n}$, inside $\mathrm{TLM}_{\mathrm{an}}$. The values used for $L$ and $r$ are respectively $35 \mu \mathrm{m}$ and $548 \mathrm{~nm}$, obtained from the FIB/SEM analysis and PSD calculation. The fitting values for $R_{S E I}$ and $R_{\mathrm{ct}}$ are highest for $\mathrm{C}$ in the delithiated form. Similarly $D$ is highest for $\mathrm{C}$ in the delithiated form which could indicate that $\mathrm{Li}^{+}$ions travel faster through the graphene planes when they are delithiated. The lithium diffusivity in the anode is observed to be around 2 orders of magnitude larger than the lithium diffusivity in the cathode.

$R_{e l}$ is extremely low and could be neglected, enabling the use of a Simplified Transmission Line Model ${ }^{15,20}$ for the graphite electrode. This is because the entire anode is made of $\mathrm{C}$ which is highly conductive. On the contrary the cathode is a mixed $\mathrm{LiFePO}_{4} / \mathrm{CB}$ electrode with a significant electronic resistance.
The values obtained for $R_{\text {ion,L }}$ for the Gr1 and LFP/CB1 electrode are comparable, which is consistent with expectations since the electrode pore volumes are comparable, see Fig. 8 and Table III. Besides the pore diameter, indicated by the analysis presented in Fig. 8, the electrode pore tortuosity $\tau_{e l}$, and pore volume / solid phase volume ratio are important factors in determining $R_{\text {ion, } \mathrm{L}} \cdot \tau_{e l}$ has been calculated as 4.7 and 1.8 for the LFP/CB1 and Gr1 electrodes respectively, using Eq. 9. The calculated tortuosity $\tau_{e l}$ for the positive electrode is close to the value obtained by TauFactor on the LFP/CB2 3D reconstruction after FIB/SEM analysis (5.9). The presence of both large particles and narrow pore necks in the microstructure of the graphite anode makes accurate estimation of the tortuosity factor infeasible using the applied FIB/SEM methodology. Illig et al. ${ }^{15}$ found for a commercial graphite electrode comparable to Gr2, a tortuosity factor of the pore phase equal to 2.72 , determined by X-ray tomography from a several orders of magnitude larger volume. This value is in a similar range as the tortuosity we obtained with the EIS modelling.

For both the anode and cathode $R_{\text {ion,L }}$ is observed to be higher in the lithiated state than in the delithiated state. This is believed to be related to the expansion/contraction of the lithiated/delithiated LFP or C particles. LFP particles are known to shrink by approximately 6.8 vol\% with delithiation ${ }^{58,59}$ and $\mathrm{C}$ particles expand 10.3 vol $\%$ with lithiation. ${ }^{48}$ The volume reduction of two adjacent LFP particles could highly influence the pores dimension (since the pore dimension is smaller than the dimension of the LFP particles), resulting in the observed significant drop of $R_{\text {ion }, L}$ after delithiation. On the contrary the expansion decreases the pore volume thereby narrowing the electrolyte diffusion channels inside the electrodes which increases the obtained modeling value for $R_{\text {ion, } \mathrm{L}}$. The relative change in the obtained values for $R_{i o n, L}$ in the lithiated and non-lithiated form is smaller for the anode than for the cathode. This is possibly because of a smaller tortuosity in the negative electrode, which results in the combined effect of a smaller relative $R_{\text {ion }, L}$ change.

Note that the selection of a TLM w/o $R_{e l}$ (due to the assumption $\left.R_{e l}<<R_{i o n, L}\right)$ implies that there is no gap on the x-axis in Figs. 12a and $12 \mathrm{~d}$ between the blue TLM $\mathrm{an}$ impedance and the green $\left(R_{l} Q_{l}\right)$ semi-circle.

26650CC impedance modelling: two-electrode configuration.Equivalent circuit description.-A new ECM is proposed to model the 26650CC spectra and shown in Fig. 14. It is a combination of the two single electrode equivalent circuits (Figs. 2 and 3). The number of variables in the model for the LFP/CB1 and Gr1 spectra is 


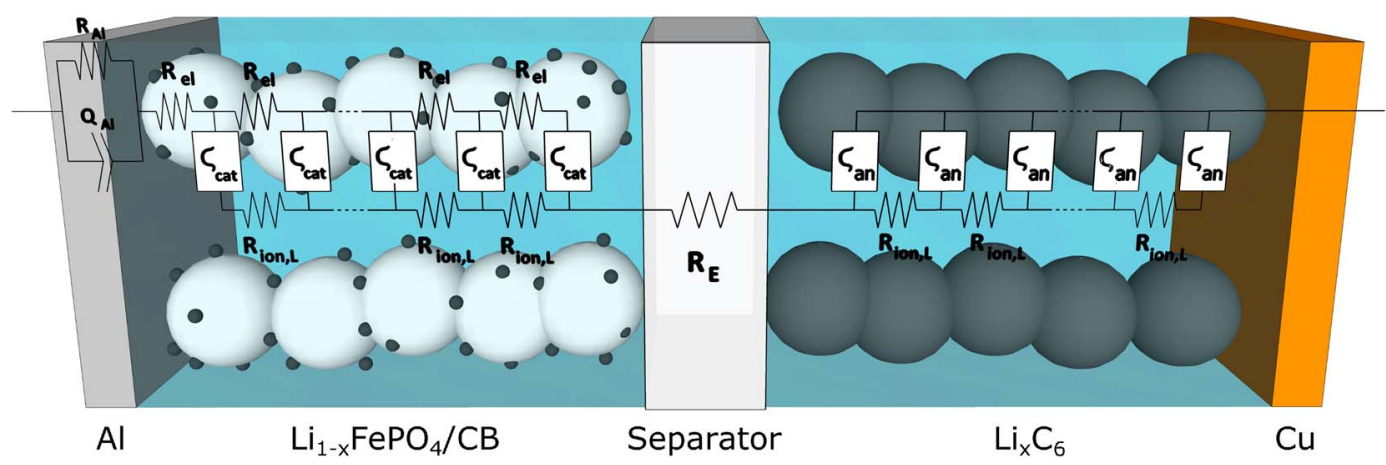

Figure 14. Schematic representation of the Equivalent circuit (ECM) used to model the 26650CC impedance spectra. It includes two TLMs used to model the two porous electrodes.

13 and 15 , respectively, and putting them in series results in a model with 23 variables. The analysis of the single electrode impedance spectra plays a crucial role for the successful modeling of the full battery since it enables us to determine the parameters that are used as guesses in the final ECM. This allows an accurate modelling of the measured 26650CC spectra. It should be noted that the single electrode models only provided input for the $0 \%$ and $100 \%$ SOC spectra. Values obtained at intermediate SOCs are obtained from the full model.

The $R_{E}\left(R_{A l} Q_{A l}\right)$ elements model the high-frequency region. $R_{E}$ models the ionic resistance of the electrolyte, while $\left(R_{A l} Q_{A l}\right)$ represents the aluminum/cathode polarization ${ }^{14}$ observed in the LFP/CB1 electrode in the frequency range $1 \mathrm{kHz}-100 \mathrm{~Hz}$. The $R_{l} Q_{l}$ element, previously used to model the particle/particle contact in the Gr1 electrode, is not included in the total circuit since this process occurs at relative high frequency $(>10 \mathrm{kHz})$, leading to a reduction in the number of model variables. Above $\sim 1 \mathrm{kHz}$ the $26650 \mathrm{CC}$ is dominated by inductance and possibly beginning skin-effects or other processes yielding also an increased real resistance. ${ }^{60}$ This contributes to the reduction.

$\mathrm{TLM}_{\mathrm{an}}$ and $\mathrm{TLM}_{\mathrm{cat}}$ model the mid- and low-frequency regions of the spectra. More specifically the mid-frequency region $(100 \mathrm{~Hz}-10$ $\mathrm{Hz}$ ) represents the SEI layer which covers each graphite particle in the anode and is described by the $R_{S E I}$ and $Q_{S E I}$ elements placed in parallel inside $S_{a n}$ (Fig. 3c). The low-frequency branch $(<1 \mathrm{~Hz})$ is ascribed to the $\mathrm{Li}$ insertion or intercalation process at the interface $\left(\mathrm{Li}_{\mathrm{x}} \mathrm{C}_{6}\right.$ or $\mathrm{Li}_{1-\mathrm{x}} \mathrm{FePO}_{4}$ ) and is modelled by the Randles circuits in $\zeta_{a n}$ and $\zeta_{c a t}$ (Figs. $2 \mathrm{c}$ and $3 \mathrm{c}$ ). The results of $R_{S E I}$ and $C_{S E I}$ obtained from TLMan are normalized for both geometrical surface area and internal surface area and reported in Table VI and in the supplementary information.

Table VI and the supplementary information also report normalized values for $R_{e l}$ (from TLM $\mathrm{TLa}_{\mathrm{cat}}$ ) and $R_{c t}, C_{d l}$ (calculated from CPE according to Eq. 5), $D$ and $R_{\text {ion }, L}$ from both TLMs.

EIS spectra fitting.-The normalized EIS spectra for $26650 \mathrm{CC}$ measured at OCV after relaxation at 0, 50 and $100 \%$ SOC, after removal of the wire inductance, are shown in Fig. 15. Figs. 15a, $15 \mathrm{~b}, 15 \mathrm{c}$ show Nyquist plots of the different EIS spectra, including best-fits to the data using the model described in Equivalent Circuit Description section, and the zoomed views of the high frequency regions in the insets. Figs. 15d, 15e, $15 \mathrm{f}$ show zoomed view of the correspondent Bode plots, including best-fits of the model to the data. Relevant values obtained by EIS modelling at the different SOCs are reported in Table VI and values for selected resistors are plotted in Figure 16. All parameter values are reported in Tables S3 and $\mathrm{S} 4$ in the supplementary information. The relative residuals and the higher zoomed views of the Nyquist plots are shown in Fig. S2 in the supplementary information.

The red semicircle seen in Fig 15 shows the impedance for the $\left(R_{A l} Q_{A l}\right)$ element assigned to the interface between the Aluminum current collector and the porous cathode. ${ }^{14}$ As reported in Table VI, $R_{A l}$ is slightly dependent of SOC. However, the values obtained for $R_{A l}$ and $C_{A l}$ are comparable to the values obtained for the same variables from the single-electrode $\mathrm{Li}_{1-\mathrm{x}} \mathrm{FePO}_{4} / \mathrm{CB}$ EIS modelling (Table IV).
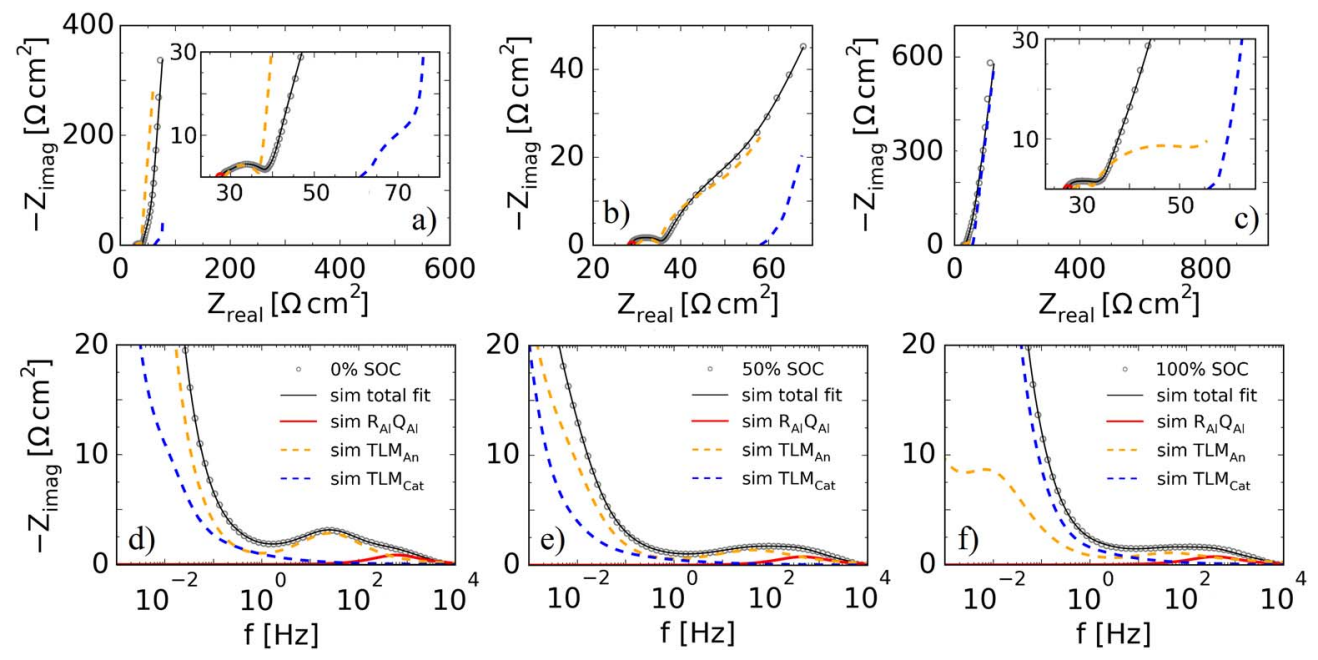

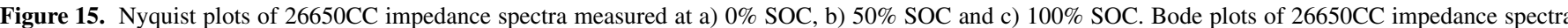

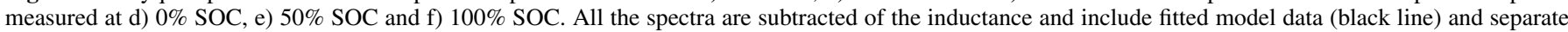
parts of the model data (blue, yellow, red). 
Table VI. Results from EIS fitting of $26650 \mathrm{CC}$. a. charging mode, b. discharging mode.

Transmission line graphite

\begin{tabular}{|c|c|c|c|c|c|c|c|c|c|c|c|c|c|c|}
\hline & & & & & & & & & \\
\hline & & \multicolumn{2}{|c|}{$\mathrm{R}_{\mathrm{Al}} \mathrm{Q}_{\mathrm{Al}}$ element } & \multicolumn{5}{|c|}{ Meyers element } & \multirow{3}{*}{$\begin{array}{l}\text { Pores } \\
R_{\text {ion }, L} \\
(\Omega c m)\end{array}$} & \multicolumn{3}{|c|}{ Randles element } & \multirow{2}{*}{$\begin{array}{l}\text { Pores } \\
R_{\text {ion }, L} \\
\end{array}$} & \multirow{2}{*}{$\begin{array}{c}\text { Electrode } \\
\qquad R_{e l}\end{array}$} \\
\hline & & $R_{A l}$ & $C_{A l}$ & $R_{S E I}$ & $C_{S E I}$ & $R_{c t}$ & $C_{d l l}$ & $D$ & & $R_{c t}$ & $C_{d l}$ & $D$ & & \\
\hline & & $\left(\Omega \mathrm{cm}^{2}\right)$ & $\left.m F c m^{-2}\right)$ & $\left(\Omega c^{2}\right)$ & $\left(\mathrm{mFcm}^{-2}\right)$ & $\left(\Omega \mathrm{cm}^{2}\right)$ & $\left(\mathrm{Fcm}^{-2}\right)$ & $\left(\mathrm{cm}^{2} \mathrm{~s}^{-1}\right)$ & & $\left(\Omega \mathrm{cm}^{2}\right)$ & $\left(\mathrm{Fcm}^{-2}\right)$ & $\left(\mathrm{cm}^{2} \mathrm{~s}^{-1}\right)$ & $(\Omega \mathrm{cm})$ & $\overline{(\Omega \mathrm{cm})}$ \\
\hline a) & $0 \%$ & 1.83 & 0.14 & 8.08 & 0.46 & 33.1 & 0.39 & $4.4 \cdot 10^{-10}$ & 247 & 22.3 & 0.68 & $5.9 \cdot 10^{-13}$ & 1464 & 123 \\
\hline & $12.5 \%$ & 1.74 & 0.22 & 5.24 & 0.40 & 28.9 & 0.72 & $5.9 \cdot 10^{-11}$ & 357 & 12.0 & 1.85 & $2.4 \cdot 10^{-13}$ & 679 & 55 \\
\hline & $25 \%$ & 1.74 & 0.19 & 5.01 & 0.37 & 26.0 & 0.81 & $5.3 \cdot 10^{-11}$ & 397 & 12.3 & 1.81 & $2.2 \cdot 10^{-13}$ & 754 & 50 \\
\hline & $37.5 \%$ & 1.72 & 0.20 & 4.78 & 0.37 & 23.4 & 0.77 & $4.7 \cdot 10^{-11}$ & 357 & 11.0 & 2.18 & $2.2 \cdot 10^{-13}$ & 828 & 45 \\
\hline & $50 \%$ & 1.74 & 0.20 & 4.77 & 0.36 & 23.6 & 0.78 & $4.8 \cdot 10^{-11}$ & 321 & 11.9 & 1.80 & $2.4 \cdot 10^{-13}$ & 810 & 40 \\
\hline & $62.5 \%$ & 1.72 & 0.18 & 4.76 & 0.36 & 25.4 & 0.77 & $5.3 \cdot 10^{-11}$ & 357 & 10.8 & 1.46 & $2.4 \cdot 10^{-13}$ & 818 & 45 \\
\hline & $75 \%$ & 1.73 & 0.24 & 4.31 & 0.40 & 23.4 & 0.65 & $5.3 \cdot 10^{-11}$ & 357 & 10.8 & 2.19 & $2.4 \cdot 10^{-13}$ & 839 & 44 \\
\hline & $87.5 \%$ & 1.75 & 0.24 & 4.25 & 0.42 & 24.0 & 0.68 & $5.8 \cdot 10^{-11}$ & 397 & 10.5 & 1.89 & $2.4 \cdot 10^{-13}$ & 752 & 36 \\
\hline & $100 \%$ & 1.69 & 0.25 & 3.10 & 0.78 & 23.9 & 0.24 & $2.7 \cdot 10^{-11}$ & 901 & 5.9 & 0.14 & $2.2 \cdot 10^{-12}$ & 935 & 32 \\
\hline b) & $100 \%$ & 1.69 & 0.25 & 3.10 & 0.78 & 23.9 & 0.24 & $2.7 \cdot 10^{-11}$ & 901 & 5.9 & 0.14 & $2.2 \cdot 10^{-12}$ & 935 & 32 \\
\hline & $87.5 \%$ & 1.79 & 0.27 & 4.34 & 0.46 & 24.1 & 0.76 & $6.2 \cdot 10^{-11}$ & 321 & 9.7 & 2.56 & $1.9 \cdot 10^{-13}$ & 752 & 36 \\
\hline & $75 \%$ & 1.79 & 0.30 & 4.37 & 0.49 & 36.6 & 0.69 & $6.9 \cdot 10^{-11}$ & 356 & 13.6 & 2.42 & $2.1 \cdot 10^{-13}$ & 717 & 32 \\
\hline & $62.5 \%$ & 1.81 & 0.33 & 4.59 & 0.41 & 36.6 & 0.90 & $6.2 \cdot 10^{-11}$ & 396 & 12.7 & 1.70 & $1.4 \cdot 10^{-13}$ & 800 & 39 \\
\hline & $50 \%$ & 1.79 & 0.36 & 4.76 & 0.38 & 37.7 & 0.78 & $6.9 \cdot 10^{-11}$ & 356 & 14.1 & 1.59 & $1.3 \cdot 10^{-13}$ & 720 & 43 \\
\hline & $37.5 \%$ & 1.77 & 0.36 & 5.12 & 0.36 & 35.4 & 0.69 & $7.6 \cdot 10^{-11}$ & 320 & 13.7 & 1.69 & $1.4 \cdot 10^{-13}$ & 648 & 42 \\
\hline & $25 \%$ & 1.75 & 0.37 & 5.26 & 0.36 & 38.9 & 0.62 & $8.5 \cdot 10^{-11}$ & 288 & 13.1 & 1.75 & $1.6 \cdot 10^{-13}$ & 720 & 52 \\
\hline & $12.5 \%$ & 1.73 & 0.51 & 5.49 & 0.37 & 35.4 & 0.59 & $1.1 \cdot 10^{-10}$ & 259 & 14.6 & 1.69 & $2.2 \cdot 10^{-13}$ & 877 & 65 \\
\hline & $0 \%$ & 1.81 & 0.14 & 8.92 & 0.45 & 38.9 & 0.32 & $4.9 \cdot 10^{-10}$ & 222 & 22.8 & 0.64 & $6.6 \cdot 10^{-13}$ & 1706 & 109 \\
\hline
\end{tabular}

The yellow dotted line shows the TLM ${ }_{\mathrm{an}}$ impedance. From the fitted values, $R_{S E I}$ decreases upon charging (Fig. 16a) in agreement with the Gr1 modeling results. In both cases $R_{S E I}$ reduces by around $60 \%$ when going from the discharged state to the charged state but for the single-electrode EIS spectra the magnitude of $R_{S E I}$ is observed to be higher. This is probably due to the buildup of a thicker SEI layer after addition of a new electrolyte in the 3-electrode configuration. As seen from the fitted values (Table VI and Fig. 16b) $R_{c t}$ and $D$ decrease with increasing SOC (or with lithiation of graphite), which is in agreement with the values obtained from the single-electrode impedance modelling. $R_{\text {ion }, L}$ is observed to slightly raise with SOC and dramatically increase in the fully lithiated graphite, because of particles expansion an pores volume reduction.

The blue dotted line represents the TLM ${ }_{\text {cat }}$ impedance. The fitted values in Table VI, and Figs. $16 \mathrm{c}, 16 \mathrm{~d}$ show how $R_{c t}, R_{i o n, L}$ and $R_{e l}$ decreases with increasing SOC (or with delithiation of LFP), in agreement with the values obtained from the single-electrode impedance modelling. $D$ is observed to be higher in the fully delithiated state.
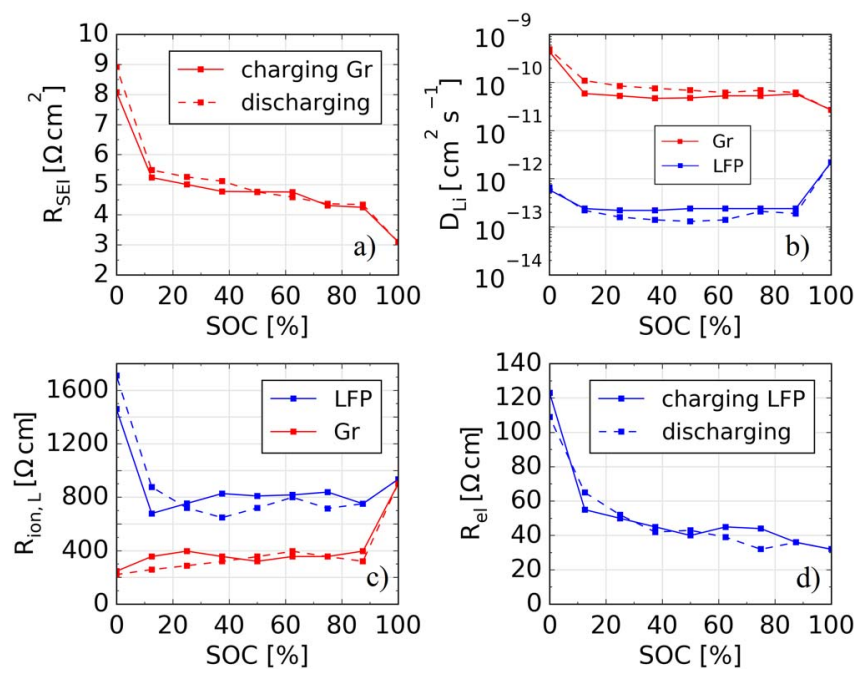

Figure 16. Fitted values as function of SOC.
From a careful analysis of Fig. 15 is possible to notice that the capacitive vertical tail, while LFP shows a diffusive tail at $0 \%$ SOC (Fig. 15a), and vice versa at $100 \%$ (Fig. 15c). This perfectly resembles the behavior observed for the single electrode impedance spectra in Figs. 11 and 12. The values for Li diffusion $D$ obtained from modeling the $26650 \mathrm{CC}$ spectrum are found to be around $10^{-12}-10^{-13} \mathrm{~cm}^{2} \mathrm{~s}^{-1}$ for LFP electrode and about 2-3 orders of magnitude larger in graphite (Fig. 16b), in agreement with previous findings. ${ }^{61}$ However larger particles size in graphite is not negligible and time constant $\tau_{w}$ is calculated using Eq. 4 for both electrodes. $\tau_{w}$ is found equal to 24,61 and $6 \mathrm{~s}$ for LFP at 0,50 and $100 \%$ SOC respectively, and equal to 7 , 59 and $120 \mathrm{~s}$ for graphite at 0,50 and $100 \%$ SOC respectively. From $\tau_{w}$ comparison is evident how the Li insertion process is diffusioncontrolled by LFP when the battery is discharged, by Graphite when charged and there is a shared contribution at intermediate SOC.

\section{Conclusions}

In this work a commercial 26650 cylindrical $\mathrm{LiFePO}_{4} /$ Graphite battery was disassembled and the two electrodes were characterized individually by charge/discharge curves and electrochemical impedance spectroscopy (EIS) in a three-electrode setup, and by FIB/SEM tomography. Two different equivalent circuits were used to model the cathode and anode impedance. The circuits included a transmission line model (TLM) for a porous electrode, which, among other parameters, involves pore length $L$ and particle radius $r$. The values for $L$ and $r$ were obtained from the FIB/SEM tomography. A thorough analysis was conducted of the parameter values obtained from fitting the individual electrode impedances. The analysis enabled us to propose a new equivalent circuit, which includes two TLMs in series, to model the full commercial battery impedance. The parameter values obtained from fitting the circuit impedance to the full battery impedance were discussed and validated against the parameter values

From fitting the ECM to the commercial battery impedance, values were obtained for the ionic resistance $R_{\text {ion }, L}$ of $\mathrm{Li}^{+}$ions diffusing into the electrodes pores, electron resistance $R_{e l}$ in the porous electrodes and lithium diffusivity in the active materials in the electrodes. By comparing the obtained values with the ones obtained from single electrode modeling, it was demonstrated that several of these paramgraphite impedance is characterized in the low frequency region by a obtained from fitting the individual electrode impedance spectra. 
eters could be distinguished and ascribed to either the cathode or the anode.

$R_{e l}$ was observed to be negligible for the anode such that $R_{e l}$ only depends on the cathode CB network. $R_{\text {ion } L}$ was seen to consist of both cathode and anode contributions and to be dependent on the SOC. Specifically $R_{\text {ion }, L}$ was observed to be highest in each of the two electrodes when they were fully lithiated. The lithium ion (or polaron) diffusion coefficient $D$ was found to be highest in both electrodes when fully delithiated and around 2-3 orders of magnitude higher in graphite than in $\mathrm{LiFePO}_{4}$. However, because of the larger particle size in graphite, the $\mathrm{Li}$ insertion is diffusion-limited in graphite when the battery is charged, and in $\mathrm{LiFePO}_{4}$ when discharged.

The new equivalent circuit proposed here, combining two TLMs and taking into account pores resistances from both cathode and anode, is used to study the low-frequency branch of commercial cell impedance spectra. Combined with other characterization techniques, it could be an important tool to study degradation mechanisms in $\mathrm{LiFePO}_{4} / \mathrm{Graphite}$ batteries when three-electrode impedance analysis in not possible.

\section{Acknowledgment}

The authors gratefully acknowledge financial support from the Danish Strategic Research Council through the project "Advanced Lifetime Predictions of Battery Energy Storage" (contract no. 060300589B)

\section{References}

1. "http://batteryuniversity.com/learn/article/types_of_battery_cells."

2. S. H. Jensen, J. Hjelm, A. Hagen, and M. Mogensen, "Electrochemical impedance spectroscopy as diagnostic tool," Handb. Fuel Cells, 6, (2010).

3. M. D. Levi and D. Aurbach, "Diffusion coefficients of lithium ions during intercalation into graphite derived from the simultaneous measurements and modeling of electrochemical impedance and potentiostatic intermittent titration characteristics of thin graphite electrodes," J. Phys. Chem. B, 101(23), 4641 (1997).

4. J. Thevenin, "Passivating films on lithium electrodes. An approach by means of electrode impedance spectroscopy," J. Power Sources, 14(1-3), 45 (1985).

5. N. Mellgren, S. Brown, M. Vynnycky, and G. Lindbergh, "Impedance as a Tool for Investigating Aging in Lithium-Ion Porous Electrodes," J. Electrochem. Soc., 155(4), A304 (2008)

6. J. P. Meyers, M. Doyle, R. M. Darling, and J. Newman, "The Impedance Response of a Porous Electrode Composed of Intercalation Particles," J. Electrochem. Soc., 147(8), 2930 (2000)

7. H. U. a Ju, J. U. N. Wu, and Y. Xu, "Revisiting the electrochemical impedance behaviour of the LiFePO4/C cathode," J. Chem. Sci, 125(3), 687 (2013).

8. F. Gao and Z. Tang, "Kinetic behavior of LiFePO4/C cathode material for lithium-ion batteries," Electrochim. Acta, 53(15), 5071 (2008).

9. P. Prosini, M. Lisi, D. Zane, and M. Pasquali, "Determination of the chemical diffusion coefficient of lithium in LiFePO4," Solid State Ionics, 148(1-2), 45 (2002).

10. J. Huang, H. Ge, Z. Li, and J. Zhang, "An Agglomerate Model for the Impedance of Secondary Particle in Lithium-Ion Battery Electrode," J. Electrochem. Soc., 161(8), E3202 (2014).

11. J. Huang, Z. Li, J. Zhang, S. Song, Z. Lou, and N. Wu, "An Analytical Three-Scale Impedance Model for Porous Electrode with Agglomerates in Lithium-Ion Batteries," J. Electrochem. Soc., 162(4), A585 (2015).

12. J. Huang and J. Zhang, "Theory of Impedance Response of Porous Electrodes: Simplifications, Inhomogeneities, Non-Stationarities and Applications," J. Electrochem. Soc., 163(9), A1983 (2016).

13. J. P. Schmidt, T. Chrobak, M. Ender, J. Illig, D. Klotz, and E. Ivers-Tiffée, "Studies on LiFePO4 as cathode material using impedance spectroscopy," J. Power Sources, 196(12), 5349 (2011).

14. J. Illig, M. Ender, T. Chrobak, J. P. Schmidt, D. Klotz, and E. Ivers-Tiffee, "Separation of Charge Transfer and Contact Resistance in LiFePO4-Cathodes by Impedance Modeling," J. Electrochem. Soc., 159(7), A952 (2012).

15. J. Illig, M. Ender, a. Weber, and E. Ivers-Tiffée, "Modeling graphite anodes with serial and transmission line models," J. Power Sources, 282, 335 (2015).

16. L. Wang et al., "Investigation of modified nature graphite anodes by electrochemical impedance spectroscopy," Int. J. Electrochem. Sci., 7(1), 554 (2012).

17. A. Funabiki, "Impedance Study on the Electrochemical Lithium Intercalation into Natural Graphite Powder," J. Electrochem. Soc., 145(1), 172 (1998).

18. J. Y. Song, H. H. Lee, Y. Y. Wang, and C. C. Wan, "Two- and three-electrode impedance spectroscopy of lithium-ion batteries," 111, 255 (2002).

19. E. Barsoukov, "Kinetics of lithium intercalation into carbon anodes: in situ impedance investigation of thickness and potential dependence," Solid State Ionics, 116(3-4), 249 (1999).

20. N. Ogihara, S. Kawauchi, C. Okuda, Y. Itou, Y. Takeuchi, and Y. Ukyo, "Theoretical and Experimental Analysis of Porous Electrodes for Lithium-Ion Batteries by
Electrochemical Impedance Spectroscopy Using a Symmetric Cell," J. Electrochem. Soc., 159(7), A1034 (2012)

21. R. Scipioni, P. S. Jørgensen, D. T. Ngo, S. B. Simonsen, J. Hjelm, P. Norby, and S. H. Jensen, "Low-voltage FIB/SEM Tomography for 3D Microstructure Evolution of LiFePO4/C Electrode," ECS Trans., 69(18), 71 (2015).

22. H. Nara, D. Mukoyama, T. Yokoshima, T. Momma, and T. Osaka, "Impedance Analysis with Transmission Line Model for Reaction Distribution in a Pouch Type Lithium-Ion Battery by Using Micro Reference Electrode," J. Electrochem. Soc., 163(3), A434 (2016)

23. J. Bisquert, G. Garcia-Belmonte, P. Bueno, E. Longo, and L. O. Bulhões, "Impedance of constant phase element (CPE)-blocked diffusion in film electrodes," J. Electroanal. Chem., 452(2), 229 (1998)

24. A. K. Padhi, K. S. Nanjundaswamy, and J. B. Goodenough, "Phospho-olivines as Positive-Electrode Materials for Rechargeable Lithium Batteries," J. Electrochem. Soc., 144(4), 1188 (1997).

25. Y. Zhang et al., "Advances in new cathode material LiFePO4 for lithium-ion batteries," Synth. Met., 162(13-14), 1315 (2012).

26. M. Ender, J. Joos, T. Carraro, and E. Ivers-Tiffee, "Quantitative Characterization of LiFePO4 Cathodes Reconstructed by FIB/SEM Tomography," J. Electrochem. Soc., 159(7), A972 (2012)

27. J. Sauvola and M. Pietikäinen, "Adaptive document image binarization," Pattern Recognit., 33(2), 225 (2000).

28. T. Kryjak and M. Gorgoń, "Parallel implementation of local thresholding in MitrionC," Int. J. Appl. Math. Comput. Sci., 20(3), 571 (2010).

29. B. Münch and L. Holzer, "Contradicting geometrical concepts in pore size analysis attained with electron microscopy and mercury intrusion," J. Am. Ceram. Soc., 91(12), 4059 (2008).

30. S. J. Cooper, A. Bertei, P. R. Shearing, J. A. Kilner, and N. P. Brandon, "TauFactor: An open-source application for calculating tortuosity factors from tomographic data.," SoftwareX, 5, 203 (2016).

31. M. Gaberscek, J. Moskon, B. Erjavec, R. Dominko, and J. Jamnik, "The Importance of Interphase Contacts in Li Ion Electrodes: The Meaning of the High-Frequency Impedance Arc," Electrochem. Solid-State Lett., 11, A170 (2008).

32. G. Garcia-Belmonte, F. Fabregat-Santiago, J. Bisquert, M. Yamashita, E. C. Pereira, and S. Castro-Garcia, "Frequency dispersion in electrochromic devices and conducting polymer electrodes: A generalized transmission line approach," Ionics (Kiel)., (5), 44 (1999).

33. R. D. Levie, "On porous electrodes," Electrochim. Acta, 9, November 1963, 1231 (1964).

34. W. C. Chueh et al., "Intercalation pathway in many-particle $\mathrm{LiFePO} 4$ electrode revealed by nanoscale state-of-charge mapping," Nano Lett., 13(3), 866 (2013).

35. R. Malik, A. Abdellahi, and G. Ceder, "A Critical Review of the Li Insertion Mechanisms in LiFePO4 Electrodes," J. Electrochem. Soc., 160(5), A3179 (2013).

36. N. Meethong, H. Y. S. Huang, S. A. Speakman, W. C. Carter, and Y. M. Chiang, "Strain accommodation during phase transformations in olivine-based cathodes as a materials selection criterion for high-power rechargeable batteries," Adv. Funct. Mater., 17(7), 1115 (2007).

37. J. L. Allen, T. R. Jow, and J. Wolfenstine, "Kinetic Study of the Electrochemical FePO 4 to LiFePO 4 Phase Transition," Chem. Mater, 19(8), 2108 (2007).

38. N. Ogihara, S. Kawauchi, C. Okuda, Y. Itou, Y. Takeuchi, and Y. Ukyo, "Theoretical and Experimental Analysis of Porous Electrodes for Lithium-Ion Batteries by Electrochemical Impedance Spectroscopy Using a Symmetric Cell," 159(7), 1034 (2012).

39. R. Younesi et al., "Analysis of the Interphase on Carbon Black Formed in High Voltage Batteries," J. Electrochem. Soc., 162(7), A1289 (2015).

40. J. Song and M. Z. Bazant, "Effects of Nanoparticle Geometry and Size Distribution on Diffusion Impedance of Battery Electrodes," J. Electrochem. Soc., 160(1), A15 (2013).

41. J. R. Macdonald, "Frequency response of unified dielectric and conductive systems involving an exponential distribution of activation energies," J. Appl. Phys., 58(5), 1955 (1985).

42. E. Barsoukov and J. R. Macdonald, Impedance Spectroscopy, 2005.

43. G. J. Brug, A. L. G. Van den Eeden, M. Sluyters-Rehbach, and J. H. Sluyters, "The Analysis of Electrode Impedances Complicated by the Presence of a Constant Phase Element," J. Electroanal. Chem., 176, 275 (1984).

44. M. Ender, A. Weber, and E. Ivers-Tiffée, "A novel method for measuring the effective conductivity and the contact resistance of porous electrodes for lithium-ion batteries," Electrochem. commun., 34, 130 (2013).

45. L. Lombardo, S. Brutti, M. A. Navarra, S. Panero, and P. Reale, "Mixtures of ionic liquid-Alkylcarbonates as electrolytes for safe lithium-ion batteries," J. Power Sources, 227, 8 (2013)

46. P. Porion, Y. R. Dougassa, C. Tessier, L. El Ouatani, J. Jacquemin, and M. Anouti, "Comparative study on transport properties for LiFAP and LiPF6 in alkyl-carbonates as electrolytes through conductivity, viscosity and NMR self-diffusion measurements," Electrochim. Acta, 114, 95 (2013).

47. T. Jacobsen and K. West, "Diffusion impedance in planar, cylindrical and spherical symmetry," Electrochim. Acta, 40(2), 255 (1995).

48. M. Winter, J. O. Besenhard, M. E. Spahr, and P. Novák, "Insertion Electrode Materials for Rechargeable Lithium Batteries," Adv. Mater. 10(10), 725 (1998).

49. C. Graves, "RAVDAV Data Analysis Software, Version 0.9.7." Technical University of Denmark, Roskilde, Denmark, 2012.

50. E. Jones, E. Oliphant, P. Peterson et al., "Scipy: Open Source Scientific Tools for Python." 2001, http://www.scipy.org/. 
51. S. van der Walt, S. C. Colbert, and G. Varoquaux, "The NumPy Array: A Structure for Efficient Numerical Computation," Comput. Sci. Eng., 13, 22 (2011).

52. J. D. Hunter, "Matplotlib: A 2D graphics environment," Comput. Sci. Eng., 9, 90 (2007).

53. F. Johansson, "mpmath: a Python library for arbitrary-precision floating-point arithmetic (version 0.18)," 2013.

54. P. Bai and M. Z. Bazant, "Charge transfer kinetics at the solid-solid interface in porous electrodes," Nat. Commun., 5, 3585 (2014).

55. C. -L. Li and Z. -W. Fu, "Kinetics of Li[sup +] Ion Diffusion into FePO[sub 4] and FePON Thin Films Characterized by AC Impedance Spectroscopy," J. Electrochem. Soc., 154(8), A784 (2007).

56. S. S. Zhang, K. Xu, and T. R. Jow, "Electrochemical impedance study on the low temperature of Li-ion batteries," Electrochim. Acta, 49(7), 1057 (2004).
57. P. L. Moss, G. Au, E. J. Plichta, and J. P. Zheng, "An Electrical Circuit for Modeling the Dynamic Response of Li-Ion Polymer Batteries," J. Electrochem. Soc., 155(12), A986 (2008).

58. A. Matasso, D. Wetz, and F. Liu, "The Effects of Internal Pressure Evolution on the Aging of Commercial Li-Ion Cells," J. Electrochem. Soc., 162(1), A92 (2014).

59. H. Lin et al., "A GGAU study of lithium diffusion in vanadium doped LiFePO 4," Solid State Commun., 152(12), 999 (2012).

60. R. R. Mosbæk, J. Hjelm, P. V. Hendriksen, and R. G. Barfod, Solid Oxide Fuel Cell Stack Diagnostics, Department of Energy Conversion and Storage, Technical University of Denmark, 2014.

61. M. Park, X. Zhang, M. Chung, G. B. Less, and A. M. Sastry, "A review of conduction phenomena in Li-ion batteries," J. Power Sources, 195, 7904 (2010). 